\title{
Siglo XIX y revolución en Veracruz. Una bibliografía básica.*
}

\author{
Carmen Blázquez Domínguez
}

\begin{abstract}
través de esta breve introducción se pretende resaltar la importancia que tienen para el "quehacer histórico" las selecciones bibliográficas como la que se presenta a continuación, sobre todo si se tiene en consideración que una de las primeras tareas que realiza el historiador, cuando se dispone a ejercer su oficio, es aquélla de recopilar el material necesario que le permitirá reconstruir las distintas fases de nuestro pasado histórico. La labor adquiere mayor relevancia cuando se pasa al campo de la historia regional, que en la actualidad se intenta enfocar desde perspectivas distintas y novedosas, porque es ahí donde la riqueza temática virgen exige la elaboración de monografías que penetren en la composición social, en las costumbres, ideología e intereses de grupo y facciones locales que conformaron toda una época.

Desde este punto de vista, la elaboración de una bibliografia básica para el estudio del siglo XIX y de las dos primeras décadas del $\mathrm{XX}$ en el estado de Veracruz, facilita no sólo una visión global sobre los procesos históricos de la entidad, sino que permite adentrarse en el examen de los mismos por medio de los testimonios de sus protagonistas, descubrir las lagunas documentales que aún existen y conocer los esfuerzos historiográficos realizados tanto por investigadores regionales, que tratan de explicar el desenvolvimiento económico, social y político de su tierra natal, como por investigadores nacionales que vinculan el acontecer local con el panorama histórico del pais.

La tarea emprendida requirió revisar minuciosamente los catálogos de bibliotecas públicas, oficiales y privadas tanto en la ciudad de México como en la de Xalapa, donde se halla la mayor parte de la.documentación relativa a la historia de Veracruz. La posterior consulta de testimonios, manuscritos, ensayos, novelas, relatos, artículos y libros llevó a concentrar material de diversa indole que mostró los periodos más conocidos y descritos, y aquéllos en los que la carencia de información es evidente. De entre todo el material obtenido se seleccionaron los títulos que se comentan.

Veracruz es un estado que por su ubicación geográfica, paso obligado en la comunicación entre la costa del Golfo y el Altiplano, y por el surgimiento de figuras locales que tuvieron un papel determinante en la política nacional, como fue el caso de Antonio López de Santa Anna, tiene un pasado rico en acontecimien-

\footnotetext{
* La conformación de esta bibliografía básica constituye parte de un proyecto desarrollado por el Instituto Dr. José Ma. Luis Mora que incluye la elaboración de una antologia de textos y documentos que reflejen la evolución política, económica y social de Veracruz a lo largo del siglo XIX y en las dos primeras décadas del siglo $\mathrm{XX}$, además de una sintesis histórica.
} 
tos, en factores y grupos sociales que, pese a su regionalismo, se vincularon en muchas oportunidades al proceso histórico nacional. Sin embargo, la búsqueda emprendida puso de relieve grandes espacios históricos que no han sido estudiados, la falta de conservación de las fuentes veracruzanas y la dispersión de las mismas.

Numerosos escritos localizados y consultados reflejan las transiciones de una sociedad que buscaba su identidad, que se organizaba dentro de los limites de la entidad, y cuyos intereses y pugnas marcan las pautas políticas y económicas, pero su periodización histórica es muy precisa: la revolución de independencia, la guerra de los Pasteles, la intervención norteamericana de 1847, la Reforma, el II Imperio, la Revolución de 1910, la intervención norteamericana de 1914. Pocos estudios locales examinan con profundidad otras etapas igualmente controvertidas como el periodo independiente en el que la figura de Santa Anna domina el panorama veracruzano, el lapso de la República restaurada o inclusive el porfiriato. Una situación similar se presenta en relación con las zonas geográficas estudiadas; muchos textos se ocupan de la región central en donde se ubican las cuatro poblaciones de mayor importancia: el puerto de Veracruz, Xalapa, Córdoba y Orizaba, circunstancia que quizá no es de extrañar si se recuerda la relevancia que tenía en el ámbito político y económico del país la primera de las poblaciones mencionadas y las dos vías de comünicación que subían a la ciudad de México. En consecuencia, algunas partes de la entidad veracruzana, que deben ser consideradas como parte integrante del desarrollo histórico local, como son la región del Coatzacoalcos, la costa de Sotavento o la Huasteca, han sido poco tratadas.

En términos generales las fuentes primarias y secundarias del estado de Veracruz no se han cuidado mucho y es de lamentar la pérdida de gran parte de ellas, como es el caso de la hemerografía del siglo xx o del material de la época que debía haberse conservado en el archivo estatal; en ocasiones, obras clásicas como la de Rivera Cambas o la de Trens hacen referencias a ensayos o escritos que ya no es posible consultar. La falta de conciencia sobre nuestro pasado histórico, aunada a la inestabilidad política y al clima de la "tierra caliente" parecen haber sido factores determinantes en esta situación y aun haber contribuido a la dispersión de libros y manuscritos. Muchas de las ediciones originales de textos considerados de gran valor para la historia veracruzana se encuentran en instituciones ubicadas en la capital, mientras que en las bibliotecas de Veracruz no se localizan o se dispone de reproducciones posteriores cuyo apego a la primera versión resulta dudoso.

Probablemente no todos los textos seleccionados puedan ser considerados como obras académicas y científicas conforme los cánones actuales, pero se pretendió presentar material que, independientemente de proporcionar una visión global de la historiografía veracruzana del siglo XIX y primeras décadas del.XX, accesible en la actualidad, pudiera servir de apoyo para la consulta de fuentes locales, como archivos notariales y parroquiales, cuyo aprovechamiento exige un marco histórico ya formado, así como la identificación de personajes y sucesos que faciliten la correlación de intereses y facciones. Algunos de ellos constituyen relatos de testigos presenciales de acontecimientos históricos específicos, 
otros reflejan las concepciones políticas, sociales y económicas de políticos e intelectuales veracruzanos, y los más describen los usos y costumbres de toda una época.

Como se ha indicado, la hemerografia del siglo XIX ha desaparecido prácticamente, y la escasa prensa que subsiste no conserva una secuencia cronológica que permita la consulta sistemática. La etapa revolucionaria, por el contrario, cuenta con el periódico $E l$ Dictamen cuya utilización es básica para el periodo. En este campo también debe mencionarse la Revista Jarocha publicada por Leonardo Pasquel que, pese a ser contemporáneo, reproduce mucho material de diversas épocas.

Las colecciones legislativas, que comprenden series de decretos y leyes emitidos por los gobiernos en turno, y las memorias de los diferentes gobernadores, cuya dispersión se ha intentado superar, resultan excelentes documentos para conocer la versión oficial de los problemas que encaraba la entidad veracruzana, para penetrar en los intereses de partido y para profundizar en la forma en que los grupos en el poder legalizaron y fortalecieron su dominación creando estructuras acordes con sus principios e ideología.

Se han reunido monografías de diversa indole que van desde obras generales clásicas, publicadas en el siglo XIX, hasta ensayos recientes que resaltan las nuevas tendencias de la historiografia veracruzana, la inclinación a analizar el desenvolvimiento histórico de Veracruz desde perspectivas novedosas y diferentes basadas en nuevas fuentes documentales o en la reinterpretación de las ya conocidas. Los textos de Manuel Rivera Cambas y de Manuel B. Trens son de consulta básica puesto que se consideran las únicas obras generales que se han realizado a la fecha. La del primero fue publicada por Ignacio Cumplido entre 1869 y 1871 , consta de 5 volúmenes y comprende el periodo que va de la independencia al fin del imperio de Maximiliano; algunos de los datos que proporciona han sido rebatidos por historiadores actuales, pero, a pesar de las deficiencias que pueda tener, la verdad es que el autor vivió los tiempos que reseña y tuvo acceso a material que hoy no se conoce. El texto de Trens fue editado por los Talleres Gráficos de la Nación entre 1947 y 1950, conformando la edición original 8 volúmenes y, aunque el último de ellos que se ocupa del porfiriato y de los indicios de la revolución, no es todo lo profundo que se desearía, la amplitud con que fueron tratados otros periodos históricos y la bibliografía utilizada compensan esa falta.

Entre los títulos comentados destacan también la producción de historiadores de prestigio cuyo interés por las cuestiones regionales viene de tiempo atrás. Entre otros están José Luis Melgarejo Vivanco, cuyo estilo está revestido de amenidad y apego a la tierra natal, y David Ramírez Lavoignet, cronista de Xalapa conocido por su gran producción de monografías regionales. Por su parte Leonardo Pasquel, si bien no tiene formación de historiador, su deseo de preservar la tradición y el pasado veracruzanos lo llevó a reproducir una multitud de manuscritos y ensayos que de otra forma se hubieran perdido.

De igual manera se seleccionaron crónicas y relatos de la vida social que brindan imágenes de la provincia, de grupos locales, costumbres y usos dejados por viajeros o diplomáticos que llegaron al pais por el puerto de Veracruz y que cruzaron la región 
central en su ascenso al Altiplano. El mismo tipo de información se obtiene de novelas costumbristas o cuentos cortos de autores como Manuel Payno, Juan Díaz Covarrubias y José Ma. Roa Bárcena.

Se encontrarán, por último, escritos de tipo variado entre los que destacan los esfuerzos de nuevas generaciones de historiadores veracruzanos por comprender, cada vez con mayor objetividad y profundidad, su pasado histórico, y las obras de temática nacional que, en su estructura, tocan de cerca los procesos históricos veracruzanos.

IIHUVX Ácosta Dominguez, Rosa Ma., La Orduña: histoc/a ria de una hacienda del siglo XVII-XX, Xalapa, Uni130 p. (Tesis de Lic. Historia) versidad Veracruzana, Facultad de Historia,'1982,

Trabájo bien documentado en el cual se presenta la evolución de la tenencia de la tierra en una región geográfica específica: Xalapa en sus alrededores. Se pretende explicar el origen, desarrollo y consolidación de la hacienda como unidad productiva en un periodo aproximado de 340 años. Se da énfasis al aspecto económico puesto que la explotación e industrialización de la caña de azúcar constituyó el centro de las actividades de la Orduña. El análisis de capitales y propietarios brinda un panorama local novedoso, de gran ayuda para la historia regional.

La estructuración de la obra es coherente y su aparato crítico se apoya en fuentes primarias locales y hemerografia, aparte de la bibliografia de rigor.

INAH Agetro, Leafar, Las luchas proletarias en Veracruz,

BNA

F392

A34

SHCP

331.88

(726.1)

A Historia y autocrítica, Veracruz, s. e., 1942, 275 p.

$\mathrm{El}$ autor de este libro intenta una explicación de las luchas proletarias en Veracruz a través de la metodología marxista. Como militante revolucionario manifiesta su intención de relatar objetivamente el desarrollo de las luchas proletarias que tuvieron lugar en el periodo de la Revolución.

El contenido puede dividirse en dos partes: la primera corresponde a los antecedentes revolucionarios, es decir, a los sucesos de Acayucan y Río Blanco, para pasar a ocuparse del Partido Comunista, su influencia en las luchas revolucionarias de Veracruz, el movimiento inquilinario, la Liga de Comunidades Agrarias y el problema religioso. La segunda parte está destinada al estudio de las organizaciones obreras y sus aspectos regionales.

Su apoyo deriva de bibliografía secundaria, y tiene un apéndice y un glosario de términos sindicales que resultan de gran utilidad.

ENV(JM)X Andrade R., Antonio, Córdoba a 350 años de su 917 C fundación, Prol. de Salvador Novo, México, s. e., 1968, 243 p.

Libro publicado para conmemorar la fundación de Córdoba y aunque no tiene gran profundidad en el tema, la parte conrrespondiente al siglo XIX proporciona breves notas bio- 
gráficas de los cordobeses más relevantes además de contener una relación de los pueblos que conformaron la población actual. No tiene indice y su apoyo bibliográfico es escaso.

\section{BCUVX Anónimo, El combate de Cosoleacaque durante la c/a intervención francesa, Xalapa, Gobierno del Es- tado de Veracruz, 1963, $37 \mathrm{p}$.}

Pequeño escrito que se concreta a relatar los acontecimientos que tuvieron lugar el 18 de octubre de 1863 en Cosoleacaque y en Minatitlán. No tiene bibliografía ni aparato crítico. Fue publicado para celebrar el primer centenario del evento que describe.

BCUVX

$\mathrm{c} / \mathrm{a}$

Anómino, Fastos militares de iniquidad, barbarie y despotismo del gobierno español, ejecutados en las villas de Orizaba y Córdoba en la guerra de once años por causa de la independencia y libertad de la nación mexicana, hasta que se consumó la primera por los tratados de Córdoba, celebrados por los Escmos., Sres. D. A. de Iturbide y de D. J. de O'Donoju, México, Impreso por Ignacio Cumplido, 1843, $77 \mathrm{p}$.

Escrito dedicado a Agustina Diez de Bonilla Tornel en que se relatan los acontecimientos que tuvieron lugar en las villas de Orizaba y Córdoba durante los años de guerras de insurgencia, lapso en el que perecieron en la región 606 personas. Fue conservado por Manuel de Argüelles, diputado al primer Congreso nacional por la provincia de Veracruz, y está estructurado cronológicamente del 5 de marzo de 1812 al 12 de mayo de 1821. Cuenta con una advertencia y se publica sin alterar el estilo.

BCUVX Anónimo, La insurgencia en la Antigua Veracruz, c/a 1812, Prol. de Leonardo Pasquel, México, Editorial Citlaltépetl, 1960, 28 p. (Colección Suma Ve-

racruzana. Serie Historiografía.)

Reproducción de un manuscrito anónimo propiedad del bibliófılo Jesús Sánchez Garza, que lo adquirió en Puebla. Se sabe que su autor fue cura en la Antigua y testigo presencial de los acontecimientos que relata en forma sencilla, enumerando a los principales insurgentes que actuaron en la región. La estructura conserva la forma de cuestionario, mismo que se formulaba a los párrocos, y las respuestas son amplias y ricas en acontecimientos locales. La ortografía de la época fue respetada y no tiene ni divisiones ni bibliografia.

\section{ENV(JM)X}

972.3

$\mathrm{P}$

IIHUVX

c/a
Anónimo, Manuscrito inédito de un testigo ocular. La guerra de independencia en la provincia de Veracruz, México, Editorial Cossío, 1943, 158 p.

La obra no es un modelo de literatura. Se dice que su autor pudo haber sido el párroco de Córdoba en los tiempos de la insurgencia. Su estilo es sencillo y sin pretensiones; relata los sucesos que se desarrollaron dentro de la región cordobesa. El manuscrito consigna los hechos que presenció el escritor siendo protagonista de 
varios de ellos, y aquéllos que le fueron referidos por otros testigos oculares. Por esta circunstancia el escrito debe considerarse como documento histórico de consulta obligada a pesar de su limitación geográfica y de las inclinaciones políticas y religiosas del posible autor.

El texto se halla dividido en cuatro partes al estilo de capitulos, y si bien una misma persona escribió toda la obra, se nota que lo hizo en tiempos diferentes. La edición consultada presenta notas a pie de página con la que los editores pretendieron suministrar información adicional que permitiera comprender mejor los sucesos reseñados y los personajes involucrados.

IIHUVX

Anónimo, Obras del puerto de Veracruz en 1882, de Leonardo Pasquel, México, Editorial Citlaltépetl, 1968, 172 p. (Colección Suma Veracruzana.

Serie Historiografía.)

El libro se ocupa de las obras de ensanche y limpia del puerto de Veracruz para las fiestas inaugurales que tuvieron lugar del 9 al 13 de agosto de 1882 así como de las actividades que desarrollaron personajes vinculados al gobierno federal y figuras locales. Cuenta con ilustraciones.

BNAL Arellano Z., Manuel, Manuel Gutiérrez Zamora, LBS

F1371

G9

A7

$\mathrm{BCACX}$

$\mathrm{C} / \mathrm{a}$ defensor de la Reforma, Prol. de Rafael Murillo Vidal, Xalapa, Editora del Gobierno, 1977, 132 p. El conocimiento de Gutiérrez Zamora, estrechamente vinculado al desarrollo histórico del Veracruz del siglo XIX, permite adquirir una serie de datos indispensables para comprender relaciones sociales e intereses politicos. El autor presenta su obra como lección de civismo y valor nacional apoyado en documentación legislativa y bibliografía secundaria. Pese a ello, es uno de los pocos escritos serios que se han realizado sobre-el liberal veracruzano.

BJDCX

972

A

A-6028

Arróniz, Joaquín, Ensayo de una historia de Ori$z a b a$. Estudio preliminar de Leonardo Pasquel, México, Editorial Citlaltépetl, 1959, 2 vols. (Colección Suma Veracruzana. Serie Historiografía.).

Se da un panorama general de la historia de la región orizabeña. El tomo útil para el estudio del siglo XIX es el segundo y solamente abarca hasta 1850 . Su descripción es sintética y el autor pretende ser imparcial ante los sucesos históricos como la injerencia de las logias masónicas en la política local, los efectos de las epidemias, la creación de la tábrica de Cocolapan. Cuenta con un epílogo, notas cronológicas comentadas, apéndice e indice general para los dos tomos.

BCUVX Arróniz, Othon, Los Tratados de Córdoba, Xalapac/a México, Editora de la Universidad Veracruzana, $1986,150 \mathrm{p}$.

Obra que revisa la gestación del pacto que señaló el inicio de la 
vida independiente de México y el papel desempeñado por dos personajes determinantes para la historia nacional: Agustín de Iturbide y Juan O'Donojú. Asimismo analiza la injerencia de las logias masónicas en el "nacimiento" de la segunda Independencia", la aparición e influencia del caudillo que dominó el escenario político mexicano durante casi medio siglo, Antonio López de Santa Anna, y la posición de los grupos sociales del puerto de Veracruz.

\section{$\mathrm{CPX}$}

972

A

BCUVX

972.61

J26A
Azcoitia, Francisco X., Páginas de la historia de Xalapa, Xalapa, Papelería e imprenta El Fénix, $1933,59 \mathrm{p}$.

El contenido de esta obra comprende desde el momento en que Xalapa obtuvo el título de villa hasta finales del siglo XIX. La estructura es poco coherente y el tratamiento de los temas disperso, si acaso siguiendo cierto orden cronológico. Sin embargo la información que proporciona puede ser de utilidad en cuanto al aspecto social de la población, a la identificación de personajes, y al conocimiento de calles y sitios públicos.

COLMEX 322.0972 B362b (1856-1875). Aspectos económicos y sociales de la revolución liberal, México, El Colegio de México, $1971,364 \mathrm{p}$.

Monografía que estudia con detalle el proceso de nacionalización y venta de bienes eclesiásticos desde 1822 hasta 1875 en el país en general y en seis estados definidos: el Distrito Federal, Puebla, San Luis Potosí, Michoacán, Jalisco y Veracruz. El análisis que se realiza en el caso de la entidad veracruzana permite examinar la movilización de la propiedad rural y urbana en la región central de la misma, así como profundizar en la composición de las sociedades locales.

IIHUVX Benítez Guevara, Socorro, La hacienda de Lucas c/a Martín a través de la historia, Xalapa, Universidad Veracruzana, Facultad de Historia, 1984, 209 p.

(Tesis de Lic. en Historia.)

El propósito de este trabajo es profundizar en el proceso de la tenencia de la tierra en la región de Xalapa. Bien fundamentado en fuentes primarias locales, como archivos notariales y parroquiales, analiza la hacienda de Lucas Martín como unidad productiva desde el siglo XVII hasta su desintegración por efectos de la reforma agraria, en las primeras décadas del siglo XX. La autora demostró con bases que su etapa de mayor esplendor se dio en el siglo XIX y su estudio permite adentrarse en el análisis de la sociedad y de la política local.

BCUVX Bermúdez Gorrochotegui, Gilberto, "Haciendas c/a del general Santa Anna registradas en el archivo notarial de Xalapa", La Palabra y el Hombre, Xalapa, Revista de la Universidad Veracruzana, núm. 52, octubre-diciembre 1984, p. 19-24. 
Artículo corto, fundamentado en material notarial, cuyo objetivo primordial es dejar constancia de las propiedades que el caudillo veracruzano adquirió en la entidad, el precio de las operaciones de compra-venta, la procedencia de los vendedores y las circunstancias que rodearon cada arreglo, manteniendo la tesis de que dichas adquisiciones fueron hechas a la sombra de su poder e influencia. El mismo estudio permite adentrarse en la sociedad local y establecer algunas de las vinculaciones santanistas.

IIHUVX Blázquez Dominguez, Carmen, "El grupo liberal c/a veracruzano del periodo juarista", Secuencia, México, Revista Americana de Ciencias Sociales, Instituto Dr. José Ma. Luis Mora, núm. 1, marzo 1985, p. 36-42.

Artículo en el que se intenta hacer ver la necesidad de utilizar nuevas fuentes documentales, como es el caso de los archivos notariales, o de reinterpretar algunas de las ya conocidas tales como los archivos municipales, para cuestionar desde otra perspectiva la composición del grupo liberal veracruzano teniendo en cuenta sus antecedentes familiares, los nexos creados de su niñez a la vida adulta, los intereses económicos en juego, las ambiciones políticás y la dominación regional. El conocimiento de estos factores facilita la identificación de figuras clave dentro de la sociedad veracruzana, así como una reconstrucción más amplia de su contexto histórico.

COLMEX

972.08

B6452m

SHUVX $\mathrm{c} / \mathrm{a}$

Blázquez Domínguez, Carmen, Miguel Lerdo de Tejada: un liberal veracruzano en la politica nacional, México, El Colegio de México, 1978, 201 p.

El propósito de la autora fue conocer con mayor profundidad el desarrollo de las actividades de este liberal veracruzano durante la época de la reforma. Se pretende establecer la relación que existía entre sus ideas politicas y económicas y su participación en la evolución histórica de México. De origen xalapeño, hizo carrera dentro del escenario de la política nacional sin perder sus vinculaciones con la tierra natal, y de aqui el interés por conocer con mayor amplitud el proceso de su ascenso político, sus intereses particulares y sus aspiraciones presidenciales.

BCUVX . Blázquez Domínguez, Carmen, "Veracruz-Perote: c/a contrata de postas, 1800-1840", La Palabra y el Hombre, Xalapa, Revista de la Universidad Veracruzana, núm. 52, octubre-diciembre 1984, p. 55-68.

Apoyada en documentación notarial, se intenta en este artículo vincular la importancia del sistema de comunicaciones que unia la costa del Golfo con el Altiplano a través de la región central de la entidad veracruzana, con el desarrollo económico de Xalapa y el fortalecimiento de un incipiente grupo de comerciantes-empresarios cuyo capital acumulado los lleva a invertir en otras actividades de la economía local. Se proporciona un cuadro de las concesiones de postas y una lista del costo de los pasajes de las diligencias que transitaban entre México y el puerto de Vcracruz. 
COLMEX

080

$\mathrm{S} 955 \mathrm{cl}$

BCACX

c/a
Calero, Carlos, Orizaba, Pról. de Leonardo Pasquel, México, Editorial Citlaltépetl, 1979, 523 p. (Colección Suma Veracruzana. Serie Historiografía.)

Amplia monografia cuyo contenido rebasa el ámbito histórico para adentrarse en otros campos como el de la salud pública, estadística, biografia, bibliografía, etc... Su autor, médico de profesión, concentró sus esfuerzos en la etapa que va de 1850 a 1950 , y pese a no reproducir una bibliografía completa, su lectura es útil para la comprensión de la región y de su sociedad.

$\begin{array}{ll}\text { BCUVX } & \text { Campomanes, José Francisco, Historia de la revo- } \\ \text { c/a } & \begin{array}{l}\text { lución para la independencia en San Antonio Hua- } \\ \text { tusco, Pról. de Leonardo Pasquel, México, Edito- }\end{array} \\ \text { CPX } & \text { rial Citlaltépetl, 1960, 60 p. (Colección Suma Ve- } \\ 972 & \text { racruzana. Serie Historiografia.) } \\ \text { C } & \text { Este libro fue editado por primera vez en } 1895 \\ \text { en Coatepec, en la imprenta de Mateo Rebolledo. }\end{array}$
Consiste en información concentrada por el padre Campomanes en 1826 procedente de las noticias que proporcionaban los clérigos seculares sobre las actividades insurgentes que observaban en sus propias jurisdicciones. No tiene introducción, ni índice ni bibliografía y su estructura es la de un informe dividido en dos partes, la primera se ocupa de los primeros brotes revolucionarios y la segunda de la consumación de la independencia.

BNAL

972.61

CAM.r.

Campos, Sebastián I., Recuerdos históricos de la ciudad de Veracruz y costa de Sotavento del estado durante las campañas de Tres Años, la intervención y el imperio, Pról. de Leonardo Pasquel, México,

BCUVX

972.61

V474c

Suma Veracruzana. Serie Historiografía.)

Una de las obras clásicas de la historia de Veracruz donde un testigo presencial analiza y relata los acontecimientos comprendidos entre 1858 y 1862 . Se halla dividida en tres partes. La primera se ocupa de la guerra de Reforma, la segunda corresponde al inicio de la Intervención francesa y la tercera toca al Imperio de Maximiliano. Se estudia cada uno de los municipios más importantes de la entidad y el autor insiste en resaltar los acontecimientos que tuvieron lugar en la costa de Sotavento. Está dedicada a Porfírio Díaz, quien la mandó publicar por conducto de la Secretaría de Fomento. No cuenta con bibliografia.

COLMEX
080
S955ce
ENV(JM)X
972
C

César, Juan N., Tlacotalpam, noticias estadísticas sobre aquella municipalidad del distrito de Veracruz, Pról. de Leonardo Pasquel, México, Editorial Citlaltépetl, 1959, 163 p. (Colección Suma Veracruzana. Serie Historiografía.)

Una de las pocas monografías que resultan de gran utilidad para el conocimiento de la vida social y económica de Tlacotalpam y que, con el uso de otro tipo de fuentes locales, permite establecer vinculaciones con diferentes intereses y facciones del siglo XIX. El autor reunió la 
información durante una visita que efectuó a la población como recabador de rentas hacia 1847 . Se percibe en el texto una gran influencia de Humboldt y se proporciona a través de él una visión bastante objetiva de la región, de sus recursos y de sus pobladores.

IIHUVX Córdoba Báez, Antonio, Breves apuntes para la c/a historia de Xico, Veracruz, s.l., Editorial Presente, 1968, 62,p.

ENV(JM)X Breves apuntes publicados con motivo de la ele972 vación de la villa Xico a la categoria de ciudad. La C mayor parte de ellos conforman una especie de apéndice que contiene información desde el año de 1844, destacando la presencia de Antonio López de Santa Anna por aquellos rumbos. Describe también, aunque en forma sintética, los primeros brotes revolucionarios en contra de la dictadura porfirista y termina con los acontecimientos de 1923. Por último se ocupa de los aspectos culturales como ferias y poesias. Carece de introducción y bibliografía.

\begin{tabular}{|c|c|}
\hline $\begin{array}{l}\text { BJDCX } \\
\mathrm{c} / \mathrm{a}\end{array}$ & $\begin{array}{l}\text { Corro R., Octaviano, El Cantón de Cosamaloa- } \\
\text { pan, noticias de geografia y de historia, Cosama- } \\
\text { loapan, Ver., Editorial La Impresora, 1951, } 251 \mathrm{p} \text {. }\end{array}$ \\
\hline $\begin{array}{l}\text { BCUVX } \\
\text { c/a }\end{array}$ & $\begin{array}{l}\text { Obra que proporciona de manera resumida una } \\
\text { infinidad de información sobre la región de Cosa- }\end{array}$ \\
\hline
\end{tabular}

BCUVX Corzo Ramírez, Ricardo, "Situaciones y nociones c/a educativas recurrentes: Veracruz, de los inicios del Porfiriato à la Revolución", La Palabra y el Hombre, Xalapa, Revista de la Universidad Veracruzana, núm. 52, octubre-diciembre 1984, p. 83-94.

Artículo en el cual se analizan los cambios que tuvieron efecto en el sistema, estructura y política educativa tanto a nivel nacional como regional en el periodo que va del porfiriato a la revolución de 1910. El autor pretende destacar, basado en documentación legislativa y bibliografia secundaria, algunas situaciones y nociones que permitan cuestionar la magnitud de los cambios emprendidos en el terreno de la educación en la etapa señalada. El resultado son indagaciones generales cuyo objetivo no es llegar a proposiciones particulares sino describir la actitud gubernamental frente al problema educativo, la instrucción primaria y la enseñanza gratuita, y el financiamiento educativo.

BNAL

630.97261

CHA.a.

IIHUVX

c/a
Chávez Orozco, Luis y Enrique Florescano, Agricultura $e$ industria textil de Veracruz, siglo XIX Fuentes para la historia económica y social de Veracruz, Xalapa-México, Universidad Veracruzana, $1965,316 \mathrm{p}$.

Consulta básica para la historia de Veracruz, el libro da un panorama muy completo sobre el desarrollo de la agricultura y de la industria textil en la entidad vera- 
cruzana. Las introducciones presentadas por ambos autores resultan de gran ayuda para la comprensión de la serie de documentos que se reproducen. El manuscrito inaugura la colección de Fuentes para la Historia Económica y Social de Veracruz y aspira, primero, a dar a conocer material inédito y muy raro para el estudio de la economía y de la sociedad veracruzana y segundo, a crear una base que sirva de punto de partida a monografías que intenten llenar la laguna que se observa en la historia de Veracruz.

COLMEX Díaz Díaz, Fernando, Caudillos y Caciques. Anto-

92

D5421c

1972

nio López de Santa Anna y Juan Alvarez, México,

El Colegio de México, 1971, 354 p.

Por la relevancia que tiene la figura de Antonio

López de Santa Anna para la historia de Veracruz

del siglo XIX. esta obra debe ser considerada dentro de la historiografía veracruzana. A partir de la definición de los dos conceptos, caudillos y caciques, con la ayuda de algunas categorías weberianas, se explora la época que va de 1810 a los albores del porfiriato a través del análisis de los dos personajes. En el caso de la figura santanista se profundiza con rigor crítico en sus antecedentes veracruzanos para poner de relieve la composición de su clientela, el alcance de su carisma y los vínculos conservados con la tierra natal a lo largo de los años de ascenso y descenso político.

IIHUVX Díaz Covarrubias, Juan, El diablo en México, La c/a clase media. Pról. de Sixto Rodriguez Hernández Puebla, Talleres Gráficos de Premiá, 1984, 124 p.

(Universidad Veracruzana. Colección Rescate, núm. 3.)

Joven escritor xalapeño de filiación liberal que en estas dos novelas cortas costumbristas utilizó el sistema artístico como elemento de critica social. Sus textos muestran una gran necesidad de despertar la conciencia real y romper con el proceso enajenante que significaba identificarse con los grupos socialmente antagónicos. Se esforzó en destruir el llamado "efecto de prestigio" sobre ciertos cánones de sensibilidad y de valores estéticos que conformaban la visión que la sociedad de su tiempo tenía del mundo.

BMRX Discursos pronunciados por los representantes de c/a los poderes puiblicos, la noche del 16 de septiembre de 1895, en la sesión inaugural del primer periodo del segundo año de la XVI Legislatura constitucional del Estado, Xalapa, Tipografía del Gobierno del Estado, 1895, 34 p.

Discursos oficiales cuyo contenido muestra algunas cuestiones locales como el reparto de terrenos comunales, los límites de Puebla y Veracruz, la reforma a la legislación civil, la industria, la educación, la introducción de agua en diversas localidades, el uso del teléfonó y la construcción de edificios públicos.

ENV(JM)X Domínguez Loyo, Miguel, La intervención y el im972.4 perio en Veracruz, Xalapa, Gobierno de Veracruz, D Universidad Veracruzana, Fonapas, 1982, 208 p.

Una de las pocas monografias actuales que se ocupa de este periodo histórico. Su estructura se apega a la secuencia cronológica, pero a veces los capítulos pierden un poco su coherencia. Sin embargo el estilo del autor es ameno, se apoya en 
fuentes documentales primarias, sobre todo del archivo de la Defensa Nacional, y proporciona una visión del estado bastante completa durante esa etapa, analizando con detalle las actividades de las guerrillas mexicanas y el impacto de la contraguerrilla francesa, las diferencias entre jefes republicanos locales y acciones relevantes como la de Camarón.

IIHUVX Domínguez Milian, Carlos, Tuxpam, capital provic/a sional del primer gobierno constitucionalista, Xalapa-Veracruz-México, Universidad Veracruzana, ENV(JM)X 1964, 93 p. (Cuadernos del Seminario de Historia 972 D Contemporánea de Veracruz.)

Trabajo monográfico que se ocupa del periodo comprendido entre 1913 y 1914 cuando Cándido Aguilar, gobernador del estado, designó a Tuxpam capital provisional del primer gobierno constitucionalista. En forma sintética el autor se refiere a los sucesos revolucionarios de la etapa y a las actividades de Aguilar dentro de los mismos.

BJDCX Domínguez Rendón, Francisco, La educación en el c/a municipio de Xalapa en el siglo XIX, Xalapa, Ediciones del Ayuntamiento de Xalapa, 1976-1979. 74 p. ENV(JM)X Con documentación primaria el autor hace una 972 relación de las escuelas que existían en Xalapa en D el siglo XIX. Pese a no contar con un gran aparato crítico la narración permite conocer el sistema educativo y la introducción de las escuelas lancasterianas. Reproduce cuadros estadísticos y cuenta con un resumen de escuelas fundadas en el siglo XVIII.

$\begin{array}{ll}\text { SHUVX } & \begin{array}{l}\text { Dominguez Rendón, Francisco, Noticias Estadisti- } \\ \text { cas de Jalapa en el año de } 1837 \text { formuladas por su } \\ \text { calustre Ayuntamiento, Jalapa, Talleres de Gráficas }\end{array}\end{array}$ Finas. 1977, 62 p. (Ediciones Ayuntamiento de Jalapa, núm. 4.)

Obra que recopila datos estadísticos de Xalapa de los primeros 37 años del siglo XIX. No tiene aparato crítico pero proporciona información inédita que puede ser utilizada en otro tipo de monografias que pretendan profundizar en los aspectos sociales y económicos de esta población.

ENV(JM)X Domíngueż Rosas, Jesús, El encanto apacible de c/a mi tierra Coscomatepec, México, Editorial Trillas, $1971,175 \mathrm{p}$.

Este escrito sirve ante todo para obtener una visión social de la región de Coscomatepec. El autor describe tanto la vida familiar, como la población en sí, sus habitantes, sus costumbres y fiestas. El capítulo medular está constituído por el relato de los sucesos revolucionarios.

BMRX

4974

cio, $1869,206 \mathrm{p}$.

Estadísticas, Noticias estadisticas de la Huasteca y de una parte de la Sierra Alta formadas en el año de 1853, México, Imprenta del Gobierno en Pala-

Trabajo elaborado para poner de relieve la riqueza de la Huasteca y su ventajosa situación entre la Mesa Central y los puertos 
de Tampico y Tuxpan. Se insiste en la facilidad de explotar la región a través de las 400 leguas de navegación interior que posee, en la construcción de caminos carreteros que unan las dos plazas portuarias mencionadas y se habla del ferrocarril de Ometusco a Tantojón o a Tanjuco. Hay también información sobre poblaciones especificas como Ozuluama, Tantoyuca, Tempoal y Chicontepec.

CPX

972

$\mathbf{F}$

Fagés, Eduardo, Noticias estadisticas del departamento de Tuxpam, Pról. de Leonardo Pasquel, México, editorial Citlaltépetl, 1959, 221 p. (Colección Suma Veracruzana, Serie Historiografía.)

ENV(JM)X

Este texto fue publicado por primera vez en 972 1854 en el Boletín de la Sociedad Mexicana de $\mathrm{F}$ Geografia y Estadística. En esta ocasión se reproduce respetando su ortografía original pero no incluye los cuadros estadisticos de la primera versión. Su valor radica en que el autor, cuya capacidad para las observaciones científicas es evidente recopiló por él mismo la información con la que compuso las noticias estadísticas. Su mayor utilidad proviene del conocimiento que se adquiere sobre los recursos naturales de. la región y sobre la población de la misma.

BCUVX c/a

IIHUVX c/a

miento agrario veracruzano que alcanzó su cenit durante la segunda administración de Adalberto Tejeda, entre 1928 y 1932 . La autora analiza los orígenes y alcances de este movimiento social teniendo como trasfondo el panorama nacional. Insiste en dilucidar los mecanismos que el gobierno central utilizó para neutralizar y desmantelar un movimiento que, en su momento, fue visto como uno de los mayores desafíos al proceso de centralización del poder posrevolucionario. Apoyada en fuentes primarias, nacionales y extranjeras, y con una amplia bibliografía, esta es otra de las obras cuya lectura es obligatoria dentro de la historiografía veracruzana.

ENV(JM)X - Ferat viuda de Zamacona, Aurora, Historia de la 972 $\mathrm{F}$ cultura en Cosamaloapan, 1845-1967, s.1., Gobierno del Estado de Veracruz, 1982, 443 p.

El objetivo de la autora es dejar testimonio de la evolución de la provincia, así como de su flora y de su fauna. La obra está dividida en dos partes: en la primera se hace un esbozo biográfico de los maestros que destacaron en Cosamaloapan y de la propia autora; en la segunda se describe la población desde su fundación hasta la fecha indicada.

BCUVX

$\mathrm{c} / \mathrm{a}$
Florescano Mayet, Sergio, "El proceso de destrucción de la propiedad comunal de la tierra y las rebeliones indigenas en Veracruz, 1826-1910", La 
Palabra y el Hombre, Revista de la Universidad Veracruzana, Xalapa, núm. 52, octubre-diciembre 1984, p. 5-18.

Artículo dividido en tres partes, con introducción y conclusiones, apoyado en memorias del gobierno de Veracruz y documentación legislativa, que plantea en términos generales el proceso de repartir y convertir en propiedad privada las tierras de las comunidades indígenas existentes en el estado de Veracruz. La medida fue puesta en práctica mucho antes que el Estado nacional adoptara las leyes de reforma creadas por el liberalismo criollo, que constituyen la culminación de pequeños pero importantes procesos regionales como el de Veracruz.

ENV(JM)X Garcia, Leandro, Juan de la Luz Enriquez, militar, c/a estadista y educador, Xalapa, Ediciones de la Escuela Normal Veracruzana, 1978, $186 \mathrm{p}$.

SHUVX $\mathrm{c} / \mathrm{a}$

Una de las pocas obras que intenta un estudio serio sobre este gobernante veracruzano cuyas actividades se extendieron desde la guerra de Reforma hasta el porfiriato. Se divide en tres partes: la primera trata de su vida militar, de 1853 a 1884; la segunda estudia sus dos periodos administrativos, 1888 a 1892; y en la tercera se analiza su labor eduçativa destacando la fundación de la Escuela Normal Veracruzana. El autor justifica su trabajo aduciendo que la biografia es un género que permite, a través del estudio de algunos personajes, penetrar en los procesos sociales y en el espíritu de una época.

IIHUVX Garcia Díaz, Bernardo, "Acción directa y poder c/a obrero en la CROM de Orizaba (1918-1922)", en Historias 7, México, Revista de la Dirección de Estudios Históricos del Instituto de Antropología e Historia, octubre-diciembre 1984, p. 15-18.

Artículo que analiza el contexto en que surgieron acciones sindicales concretas en un periodo de ascenso de la lucha de clases que vivió Veracruz en los años 20 . Se describe cómo en esos años se llevó a cabo, en la región de Orizaba, la irrupción organizada y violenta de las clases subalternas en busca de la conquista de sus reivindicaciones durante los gobiernos radicales de Cándido Aguilar, Adalberto Tejeda y Heriberto Jara.

IIHUVX Garcia Diaz, Bernardo, Un Pueblo Fabril del Porc/a firiato: Santa Rosa. Veracruz, México, SEP/FCE, núm. $80,1981,167 . p$.

Este ensayo se sitúa en el marco de la dictadura porfirista y examina la formación del poblado de Santa Rosa, Veracruz, desde sus antecedentes remotos hasta el momento en que se da el levantamiento de obreros textiles contra sus patrones. Analiza la transformación de las estructuras económicas, sociales, políticas y culturales y las agudas contradicciones generadas por la rápida expansión capitalista, muestra de una rigurosa interpretación que desborda el límite geográfico señalado por el autor para intentar penetrar en la formación de la conciencia obrera de una vasta región del país. Dividido en tres capitulos, que van del porfiriato al inicio de la Revolución, cuenta con un apéndice que señala la mi- 
gración laboral por estados y varios mapas sobre la ubicación de las fábricas textiles de Orizaba, lugares de origen de los fundadores del pueblo de Santa Rosa, gráficas de migración e itinerarios de la revuelta de 1907 que tuvo lugar en el mismo. Entre las fuentes utilizadas destaca la serie de entrevistas realizadas.

IIHUVX García Islas, Sara, El Jagüey de las ruinas, Pról. de c/a Jorge Ruffinelli, Puebla, Talleres Gráficos de Premiá, 1985, 147 p. (Universidad Veracruzana. Colección Rescate, núm. 9.)

Novela de estilo sencillo y suave que cuenta la historia de una familia de la Huasteca veracruzana, los Jáuregui, a lo largo de algunas generaciones de la primera mitad del siglo XIX pero centrada en la etapa de la intervención francesa o segundo Imperio. Basada en hechos reales tomados de los archivos del municipio de Ozuluama y de alguna bibliografía secundaria, mezcla en ellos la ficción y constıtuye un testımonıo de pasiones, contlictos y personajes, reflejo de una sociedad que tiende a transformarse en nacional, abandonando su criollismo. Reúne además grandes méritos por las descripciones de la población y del paisaje de una región veracruzana cuyas fuentes históricas se han perdido en su gran mayoria.

SHUVX García Morales, Soledad, El conflicto clerical en c/a Veracruz en 1931, Xalapa, Facultad de Humanidades, Universidad Veracruzana, 1974, $137 \mathrm{p}$.

Monografía que comprende el periodo de 1929 a 1931 y que analiza el enfrentamiento que tuvo lugar en la entidad veracruzana entre el poder eclesiástico local y el gobernador en turno, Adalberto Tejeda. La consulta del archivo personal de Tejeda permitió examinar la posición de las facciones involucradas en el conflicto, los intereses regionales en juego y la injerencia del gobierno central en los problemas locales. La autora, quizá con cierta inclinación hacia la postura tejedista, describe las causas que originaron la expedición de la ley 197 por medio de la cual se pretendía poner limite a la influencia eclesíastica sobre el pueblo, de manera que fuera posible continuar la restructuración social que Tejeda había iniciado a través del fortalecimiento del campesinado y de la clase obrera.

SHUVX Garcia Morales, Soledad, "Oposición al primer c/a gobierno tejedista (1920-1924)", Revista de Investigaciones Históricas, Xalapa, Seminario de Historia, núm. 1, 1979, p. 22-35.

La autora dividió su texto en cuatro partes a través de las cuales examina las diferencias existentes entre Alvaro Obregón, ya presidente de la República, y Adalberto Tejeda, gobernador radical veracruzano. Si bien el primero aprobaba reformas sociales, tambièn se inclinaba por establecer un equilibrio entre las fuerzas sociales, entre hacendados y trabajadores; es decir, las reformas sociales no significaban para él cambios profundos dentro del sistema que pudieran constituir un peligro para los intereses del sector capitalista. Las diferencias se acentuaron en lo referente al sector agra- 
rio, dado que Tejeda se pronunciaba por la práctica efectiva de los artículos 27 y 123 y por la división de la tierra. La documentación utilizada, sobre todo del archivo personal de Adalberto Tejeda, permite reconstruir las circunstancias que rodearon las disputas de ambos ejecutivos y la forma en que afectaron el desarrollo histórico regional.

BCUVX Garcia Morales, Soledad, "El ferrocarril de tracc/a ción animal Jalapa-Coatepec, 1875-1880", $\mathrm{La} \mathrm{Pa}$ labra y el Hombre, Xalapa, Revista de la Universidad Veracruzana, núm. 52, octubre-diciembre 1984, p. 25-34.

El contenido de este texto se concentra en la construcción de una vía férrea local, ligada a los intereses económicos de ciertos grupos xalapeños y coatepecanos y cuyo tendido responde a la política nacional puesta en marcha durante la República restaurada: conservación, mejoramiento y ampliación de las redes de caminos existentes. No sólo se buscaba el transporte de pasajeros sino una vía de salida para la producción regional proveniente de haciendas vecinas como la Orduña, Zimpizahua, Tuzamapan y Mahuixtlán. El artículo cuenta con un inventario de las propiedades del ferrocarril y con un mapa del municipio de Coatepec.

INAH Garcia Mundo, Octavio, El movimiento inquiliLBA nario en Veracruz, 1922, México, SepSetentas, AC70 núm. $269,1976,175 \mathrm{p}$.

S4 Se pretende estudiar la fase anarquista que perv. 269 mitió el surgimiento del movimiento inquilinario y las contradicciones existentes entre el poder regional, representado por Adalberto Tejeda, y el gobierno federal. Se insiste en el fracaso del sindicato de inquilinos y se examinan detenidamente los factores que influyeron en esa situación y que culminaron con la matanza del 6 de julio de 1922 .

SHUVX Gavira, Gabriel, Su actuación político-militar rec/a volucionaria, Xalapa, Editora del Gobierno de Veracruz, $1982,259 \mathrm{p}$.

Apuntes de tinte biográfico, que proporcionan la visión del Veracruz revolucionario. Gavira fue uno de los iniciadores del movimiento en la entidad, y desarrolló aquí sus actividades hasta que sus diferencias con Cándido Aguilar, otro revolucionario veracruzano , lo obligaron a dejar el estado. La lectura de la obra es importante porque el autor narra sus propias experiencias y da su versión particular de circunstancias y hechos determinados.

BCUVX González de Cossío, Francisco, Xalapa, breve re972.61 seña histórica, México, Talleres Gráficos de la NaJ26G ción, 1957, $488 \mathrm{p}$.

Una de las mejores monografias que se conocen $\mathrm{CPX}$ 972 G sobre la ciudad de Xalapa, fundada en fuentes primarias y con un buen análisis crítico sobre el desarrollo de la población. El autor inicia la obra desde los tiempos prehispánicos y llega hasta el final de la revolución. Se proporciona un apéndice de documentos y testimonios, una lista de gobernadores y una amplia bibliografía. 
BCUVX

$\mathrm{c} / \mathrm{a}$

IIHUVX

$\mathrm{c} / \mathrm{a}$
Herrera Canales, Inés, El Comercio Exterior de México 1821-1875, México, El Colegio de México, $1977,193 \mathrm{p}$.

Dada la importancia que tuvo para el puerto de Veracruz y para la entidad veracruzana en general el desarrollo del comercio interior y exterior del país, la obra es de gran ayuda para la historia regional. Intenta caracterizar al comercio exterior de México precisando las particularidades que presenta en una etapa de expansión del comercio europeo hacia el resto del mundo, expansión que busca mercados para la producción industrial creciente. Se analiza la embestida de las potencias industrializadas y la permanencia de la estructura productiva colonial que frenó toda posibilidad de desarrollo autónomo y que conformó el patrón neocolonial mexicano del siglo XIX. Se utiliza una variada bibliogafía y se proporciona un anexo y numerosas gráficas ilustrativas del proceso que se estudia.

COLMEX

080

S955h

BCUVX

972.61

$\mathrm{C} 796 \mathrm{H}$

Herrera Moreno, Enrique, El cantón de Córdoba, apuntes de geografia, estadistica e historia, México, Editorial Citlaltépetl, 1959, 2 vols. (Colección Suma Veracruzana. Serie Historiografía.)

En principio estos apuntes fueron producto de una sociedad formada para conservar el pasado histórico y cultural de Córdoba. Como el proyecto no funcionó, el autor, comisionado para recoger la información necesaria, la publicó por su cuenta bajo el título que se comenta.

Con una base de archivos locales y testimonios orales se relata la historia del cantón desde la conquista hasta la república restaurada y se proporcionan noticias de interés sobre los municipios, "el clima, la producción. El estilo de la obra es narrativo y carece de interpretación histórica, pues la formación de quien lo escribe no era de historiador sino de médico.

SHCP Herrera Moreno, Enrique, Historia de la educa373 (726.1)

$\mathrm{H}$ ción secundaria en el Estado de Veracruz, Xalapa, Oficina Tipográfica del Gobierno del Estado, 1923, $418 \mathrm{p}$.

Síntesis sobre educación secundaria que comprende desde 1825 hasta 1921 . No tiene bibliogra-

ENV(JM)X fía pero el autor señala que consultó archivos loca-. 373

H les y que utilizó testimonios orales.

Consta de un apéndice y no tiene aparato crítico mas se indica que el propósito del texto es servir de base a nuevas investigaciones históricas que pretendan profundizar en el análisis de la educación veracruzana.

ENV(JM)X Iglesias, Andrés, Soteapan en 1856, Pról. de Leo$\mathrm{c} / \mathrm{a}$

Antropología.) nardo Pasquel, México, Editorial Citlaltépetl, 1973, 29 p. (Colección Suma Veracruzana. Serie

Reproducción de un escrito elaborado en 1850 y referido a la sierra de Soteapan y a sus habitantes. El examen, de tipo antropológico, fue publicado por primera vez en un periódico de Veracruz 
y posteriormente en el tomo III del apéndice al Diccionario Universal de Historia y Geografía impreso también en 1850 . Su ortografia se ha respetado, carece de bibliografía por ser una relato directo y su redacción obedeció a la influencia que despertaban los proyectos de tránsito por el istmo de Tehuantepec tan en boga en el siglo XIX.

IIHUVX Iglesias, José Ma., Acayucan en 1831, Pról. de c/a Leonardo Pasquel, México, Editorial Citlaltépetl, Historiografia.) 1966, 122 p. (Colección Suma Veracruzana. Serie

El título de esta obra fue elegido por Pasquel para la reimpresión de una parte de la Estadística del Estado Libre y Soberano de Veracruz publicada en 1831 , la correspondiente a los tres cantones del departamento de Acayucan. En cierto modo Iglesias sólo fue su autor circunstancial ya que dio forma al texto porque en esa época se desempeñaba como jefe interino del citado departamento, y únicamente acató la disposición que ordenaba la formación de una estadística. El texto contiene información de Acayucan, Huimanguillo y San Andrés Tuxtla en relación a su situación económica, politica y social.

BJDCX Illescas, Francisco R. y Juan Bartolo Hernández, c/a Escritores veracruzanos, reseña biográfico-antológica, Veracruz, Imprenta Veracruz, 1945.

El texto tiene como propósito dar a conocer a los hombres que han dado lustre al estado de Veracruz, como estímulo a la juventud de México. Muchos escritores que figuran en esta obra nacieron en el estado de Veracruz, pero su cultura pertenece a la ciudad de México y al extranjero; sin embargo en Veracruz también existen valores literarios de gran relieve, cuyos nombres no se incluyen porque no nacieron en este estado. Tampoco se tomaron en cuenta las escuelas literarias, sino que sólo se inserta una galeria de escritores firmes, de prestigio, fama, algunos olvidados por la ingratitud humana... Los biografiados son jesuitas, románticos, clásicos latinos, modernistas, líricos, dramaturgos, etc. Tiene índice alfabético de escritores, clasificación de escritores por materia y abundante bibliografía secundaria.

\begin{tabular}{|c|c|}
\hline $\begin{array}{l}\text { IIHUVX } \\
\text { c/a }\end{array}$ & $\begin{array}{l}\text { Isassi, José Domingo, Memorias de lo acontecido } \\
\text { en Córdoba en tiempos de la revolución para la his- } \\
\text { toria de la independencia mexicana. } 1827 \text {. Pról. de }\end{array}$ \\
\hline $\begin{array}{l}\text { CPX } \\
972 \\
1\end{array}$ & $\begin{array}{l}\text { Leonardo Pasquel, México, Editorial Citlaltépetl, } \\
1960,75 \text { p. (Colección Suma Veracruzana. Serie } \\
\text { Historiografia.) }\end{array}$ \\
\hline $\begin{array}{l}\text { ciones q } \\
\text { doba, en } \\
\text { insurgen } \\
\text { cia. El te } \\
\text { siguiente }\end{array}$ & $\begin{array}{l}\text { El manuscrito de Isassi surgió por las informa- } \\
\text { tó el obispo de Puebla a los sacerdotes de Cór- } \\
\text { ue se hallaba el autor, sobre las actividades de los } \\
\text { región, para formar la historia de la independen- } \\
\text { bó de redactarse en } 1826 \text { y fue publicado al año } \\
\text { Al igual que el escrito de Campomanes, resume } \\
\text { le } 1812 \text { a } 1821 \text { y constituyen la crónica de un }\end{array}$ \\
\hline
\end{tabular}


BCUVX

c/a

Keratry, Emile de, La contraguerrilla francesa en

México, 1864, México, SEP/FCE, núm. 12, 1981, $178 \mathrm{p}$.

La falta de monografías que se ocupen de estudiar el desarrollo histórico veracruzano en la época del II Imperio, hace necesario recurrir a escritos de corte nacional como el presente. Esta obra analiza el surgimiento de las guerrillas mexicanas como reacción a la dominación francesa y su consecuencia directa: la formación de contraguerrillas extranjeras en las que aunque formadas en gran parte por franceses, habia también individuos de otras nacionalidades que en su mayoria habian dejado la tierra natal en busca: de una fortuna rápida. Keratry, quien perteneció a dichas contra-: guerrillas, relata la forma en que se desarrolló la guerra de guerri-r llas en el estado de Veracruz en torno a la región central, donde se ubicaba el sistema de comunicaciones que vinculaba la costa del Golfo con el Altiplano, y en torno a la del norte de la entidad, en. la Huasteca, identificando figuras y acontecimientos locales.

ENV(JM)X Klunder, Juan y Alberto Uruñuela, Reseña históc/a rica del palacio municipal de Veracruz, 1609-1914, s.p.i.

El objetivo de este libro es describir los sucesos más notables sobre el palacio municipal de Veracruz, que tuvo su origen en 1609.

Para mejor comprensión, el autor dividió su estudio en tres periodos, a saber: Antiguo, Moderno y Contemporáneo. El primero abarca desde su inicio o erección hasta el año de 1914; de esta fecha hasta 1933 en que se encontraba en ruinas es el segundo, y, por último el de su restauración y embellecimiento que comprende desde el año de 1934 hasta 1935 en que se lleva a cabo la investigación.

Tiene un cuadro sinóptico del H. Ayuntaminento de Veracruz de los años 1934 y 1935, así como las fotografias de sus integrantes y del palacio; una breve descripción sobre su construcción. La bibliografía es general.

ENV(JM)X Knapp Jr., Frank A., Sebastiain Lerdo de Tejada, 923 Traducción de Francisco González Arámburo, K Xalapa-México, Universidad Veracruzana, 1962,

Letras, núm. 11.) 434 p. (Biblioteca de la Facultad de Filosofía y

El libro se publicó por primera vez en inglés en 1951 y. su autor trata de explicar la influencia que tuvo el personaje a lo largo de la intervención francesa y la República restaurada. Probablemente es uno de los mejores análisis biográficos que se haya hecho de una figura veracruzana que alcanzó la silla presidencial. A pesar de que el autor declara que uno de sus principales obstáculos fue la carencia de información, su obra se funda en una amplia consulta de fuentes primarias y secundarias que permiten realizar un estudio completo y detallado de Lerdo de Tejada.

BCưVX Kolonitz, Condesa Paula, Un viaje a México en c/a I864, México, SepSetentas, núm. 291, 1976, 190 p.

La autora formó parte del séquito de la empera- 
triz Carlota y con ella desembarcó en el puerto de Veracruz el 28 de mayo de.1864. Permaneció en nuestro país por espacio de seis meses y sus observaciones sirvieron de base a esta obra, publicada en Viena tres años más tarde, en 1867. A través de sus páginas, y en lo que se relaciona con el contexto veracruzano, la condesa deja constancia de sus impresiones sobre la sociedad local, el estado de las poblaciones por las que transitó y su paisaje. Pese al desdén que en ocasiones dejan traslucir sus opiniones, la lectura del manuscrito resulta fácil y en ocasiones divertida.

BMRX Las tarifas del ferrocarril de Veracruz, colección de c/a artículos sobre el convenio de 15 de marzo de 1873, entre el ejecutivo de la Unión y la compañia de ferrocarril de Veracruz, publicados en el siglo XIX por Emilio Velasco, México, Imprenta de Ignacio Cumplido, 1872, 129 p.

Libro estructurado por articulos, del 1 al 14. Incluye un convenio celebrado entre el Ministerio de Fomento y la compañia del ferrocarril mexicano. Se refiere a las tarifas de México a Veracruz. En el convenio se autoriza a Ramón Zangroniz a seguir construyendo y a explotar por su cuenta durante 65 años un ferrocarril entre Veracruz y Puebla, pasando por Perote y Xalapa.

Se incluyen las memorias de guerra y marina y la memoria de la Cámara de Comercio española en México.

BMRX

323.354

L4f8c

León Fuentes, Nelly Josefa, Conformación de un capital en torno a la caficultura en la región $\mathrm{Xa}$ lapa-Coatepec, 1890-1940, Xalapa, Universidad Veracruzana, Facultad de Historia, 1983, 203 p.

(Tesis de Lic. en Historia.)

Trabajo centrado en el proceso de acumulación de capital de un finquero de la región de Coatepec, Justo Fernández González. Análisis de la explotación del café y sus vinculaciones regionales que lleva al examen de la sociedad local.

COLMEX Lerdo de Tejada, Miguel, Apuntes históricos de la CE heroica ciudad de Veracruz, México, Imprenta de 972.61 Ignacio Cumplido, 1850, 3 vols.

L615a Obra clásica que refleja el pensamiento y las concepciones liberales de su autor. El objetivo principal fue presentar una memoria de lo que había sido el puerto de Veracruz desde su origen con la esperanza de' que el conocimiento y la comparación de las épocas históricas, y el examen de las causas de la decadencia observada para mediados de siglo, despertara el interés de los veracruzanos de buscar su mejoramiento. No se tenía la pretensión de hacer una historia pero sí de establecer relaciones con situaciones que afectaban la economía y la política de su momento. La obra se inicia en 1492 y llega hasta 1857, año en que Lerdo de Tejada había dejado la cartera de Hacienda. Cuenta con numerosos cuadros estadísticos y una buena descripción de la ciudad de Veracruz.

IIHUVX Lerdo de Tejada, Miguel, México en 1856. El"coc/a mercio exterior desde la conquista, Pról. de Carmen Blázquez Dominguez, Puebla, Talleres Gráfi- 
cos de Premiá, 1985, 160 p. (Universidad Veracruzana. Colección Rescate, núm. 6.)

Se reproducen aquí integros, tres de los escritos menos conocidos del autor: Cuadro Sinóptico de la República Mexicana en 1856. Informe del Ministerio de Fomento y Camino de Fierro entre Veracruz y México, y el estudio introductorio de su libro más comentado: El Comercio Exterior de México. El prólogo contiene un análisis biográfico de Lerdo, liberal veracruzano de prestigio y carrera nacionales, autor de la ley de Desamortización promulgada en 1856, y el examen de su producción literaria. Los textos reproducidos proporcionan la visión del país hacia la primera mitad del siglo XIX y algunas cuestiones relacionadas con Veracruz como población, recursos y construcción del ferrocarril.

COLMEX

309.172

L8641e
López Cámara, Francisco, La Estructura Económica y Social de México en la época de la Reforma, México, Siglo XXI, 1867, 244 p.

Obra de lectura indispensable para la comprensión de la guerra de Tres Años fundada en una vasta recopilación de fuentes y materiales históricos. La temática está centrada en la reconstrucción histórica de la estructura económica y social de México en la época que conoció el triunfo definitivo del movimiento liberal republicano. Proporciona la visión de un país en crisis cuyas contradicciones parecian conducirlo al fracaso total, pero también describe la dialéctica de factores, entre los que destaca el movimiento liberal, que lograron su salvación. Aunque en general casi todos los capítulos resultan de gran utilidad para comprender el desarrollo histórico de Veracruz aunado al proceso nacional, los capítulos cuarto y quinto se ocupan de una de las primordiales actividades económicas de la entidad, el comercio, y de su población más importante, el puerto de Veracruz.

COLMEX

M863.4

L8649h

López Fuentes, Gregorio, Huasteca, México, Ediciones Botas, 1939, $324 \mathrm{p}$.

Novela situada en el periodo histórico que comprende la formación y actividades de las compañías deslindadoras y la etapa revolucionaria en la Huasteca. Describe las costumbres del campo y la vida del hacendado vinculadas a un factor nuevo, la explotación petrolera. Analiza a través de la ficción el impacto del petróleo y la forma en que la mentalidad y los intereses van cambiando. Examina también la influencia de las compañias deslindadoras, de las empresas petroleras y de los Estados Unidos en la caida del régimen maderista.

INAH

BNA

F92

V4

L6

López Ituarte, Alfonso, Satanás. Novela histórica sobre la invasión de Veracruz en 1914. Pról. de Leonardo Pasquel, México, Editorial Citlaltépetl, 1964, 193 p. (Colección Suma Veracruzana. Serie Letras.)

Pese a la ficción de su contenido, los datos históricos abundan porque su autor fue testigo presencial y combatiente mexicano. Refleja tres modos de vida: la rutina del campo, las actividades cotidianas en la revolución, y la vida durante la ocupación, dando así forma al escenario histórico de la ocupación de Veracruz por las fuerzas norteamericanas en 1914. 
ENV(JM)X Mancisidor Ortiz, Anselmo, Heriberto Jara, Xac/a lapa, Dirección General de Educación Popular, $1978,143 \mathrm{p}$.

A través de esta obra se explica la participación de Heriberto Jara en la revolución maderista y su actuación como militar y como gobernador de Veracruz en 1924. No tiene bibliografia pero compensa esta deficiencia con el hecho de que el autor convivió con el personaje y en su narración quedan plasmadas sus experiencias.

ENV(JM)X Mancisidor Ortiz, Anselmo, Veracruz recuperado, $\mathrm{c} / \mathrm{a}$

México, s.e., 1968, 174 p.

Serie de artículos que tienen como finalidad conmemorar la invasión del puerto de Veracruz por fuerzas norteamericanas en 1914. La introducción relata los acontecimientos históricos de ese año en el estilo ameno que caracteriza a este autor veracruzano. No tiene bibliografia.

BJDCX Marin H., Miguel, Orizaba a principios de siglo, c/a Pról. de Leonardo Pasquel, México, Editorial Cizana. Serie Miscelánea.) tlaltépetl, 1967, 27 p. (Colección Suma Veracru-

Breve texto en el que se pretende resaltar el progreso económico y cultural que tuvo Orizaba en el siglo XIX y principios del XX. El autor describe la industrialización de la región, sobre todo textil, la llegada del ferrocarril y el fomento a la educación, alabando al gobierno "honrado y progresista" de Teodoro Dehesa.

IIHUVX Martínez Alarcón, Juana, San Cristóbal: un ingec/a nio y sus trabajadores. 1896-1934, Xalapa, Univer1985, 158 p. (Tesis de Lic. en Historia.)

sidad Veracruzana, Facultad de Antropologia,

El objetivo principal del trabajo fueron los cambios operados en la empresa del ingenio de San Cristóbal en la década de los años 20 y su relación con el contexto laboral. El trabajo está estructurado en dos partes. La primera comprende el análisis del ámbito económico social en el que surgió la empresa y las circunstancias históricas que condicionaron su evolución hasta 1917. La segunda parte examina el aspecto obrero, recalcando la organización de los trabajadores. Es un estudio monográfico que permite penetrar algunos aspectos de la economía y de la sociedad regional.

SHUVX Mata, José Ma. Correspondencia privada de... con c/a D. Melchor Ocampo, Morelia, Tipografia Mercantil de S. R. L., 1959, 248 p.

Epistolario que revela el vinculo existente entre este liberal veracruzano y el "fílósofo de la Reforma", Ocampo, poniendo de relieve el espíritu de dos épocas: el de la revolución de Ayutla y el de la guerra de Reforma. Por otro lado, las misivas proporcionan una serie de datos sobre acontecimientos y figuras locales que facilitan el estudio de la sociedad y de la política veracruzana. El libro se divide en dos partes con un excelente prólogo de Jesús Romero Flores en el que se hace un análisis biográfico de Mata. 17 cartas corresponden al periodo del exilio (de 1854 a 1855), 48 
a la etapa del Congreso Constituyente (1856-1857) y 62 a la guerra civil (1858-1860).

INAH Meade, Joaquín, La Huasteca Veracruzana, Pról.

LBA

F1294

V4

M4

BCUVX

972.61

H874M

de Leonardo Pasquel, México, Editorial Citlaltépetl, 1962, 2 vols. (Colección Suma Veracruzana. Serie Historiografia.)

El texto está centrado en el análisis de cuatro excantones: Chicontepec, Ozuluama, Tantoyuca y Tuxpan, y es el segundo volumen el que resulta de gran utilidad para el estudio de la Huasteca en el siglo $\mathrm{XIX}$ y en las dos primeras décadas del siglo

$x x$. Proporciona una abundante bibliografia y es de las pocas monografias que se ocupan de esta área geográfica.

INAH Medel y Alvarado, León, Historia de San Andrés LBS

F1391

S3

M4

Tuxtla, 1532-1950. Pról. de Leonardo Pasquel, México, Editorial Citlaltépetl, 1963, 2 vols. (Colección Suma Veracruzana. Serie Historiografía.)

Catalogada como obra de consulta básica para la costa de Sotavento, esta historia muestra una ENV(JM)X gran recopilación de material al que se dio cierto 972 orden temático y cronológico. Su contenido abarca M más de tres siglos y su autor, que insiste en indicar su falta de preparación como historiador, pretende despertar el interés de los especialistas para la elaboración de trabajos de investigación más profundos. Proporciona una bibliografía formada por fuentes primarias y secundarias y reproduce también testimonios orales.

IIHUVX Melgarejo Vivanco, José Luis, Boquilla de Piedra, c/a el puerto de la insurgencia, Xalapa-México, Editora del Gobierno de Veracruz, 1976, 133 p.

Pequeña monografía producto del hallazgo de un expediente sobre Boquilla de Piedra que se halla en el Archivo General de la Nación. El autor, con su particular estilo y soltura, realiza un examen tanto de la ubicación geográfica de este punto como de sus antecedentes históricos, para ocuparse después de su aparición como reducto de las partidas insurgentes comandadas por Victoria y Rincón. Así, se resalta la importancia que tuvo como baluarte que proporcionó a los rebeldes veracruzanos una vía de acceso al mar, una vía de abastecimiento. Se reproducen también tres mapas de la costa del Golfo y una bibliografia minima.

BNAL

972.61

MEL.b.

1975 general sobre la historia de Veracruz, desde los IIHUVX primeros pueblos indígenas hasta la revolución c/a mexicana, iniciándolos con una explicación sobre la demarcación de los pueblos desde la prehistoria

hasta 1905.

Melgarejo Vivanco, José Luis, Breve historia de Veracruz, 2a. ed., Xalapa, México, Editora del Gobierno de Veracruz, 1975, $268 \mathrm{p}$.

Reedición, en que el autor nos da un panorama

La obra está dividida en la siguiente forma: demarcación, lo 
indigena, conquista, la colonia, independencia y revolución. No tiene introducción ni conclusión, por eso no fue posible encontrar el propósito del autor, ni a quien la dirige. Trata diversos temas en cada una de las épocas. No tiene bibliografia.

BNAL Melo de Remes, Ma. Luisa, Veracruz mártir, la inR famia de Woodrow Wilson (1914), México, s.e., $972.093 \quad 1966,191 \mathrm{p}$.

MEL.V. Aunque el tono de este texto es un tanto apologético, la autora recurrió para la recopilación de información a testimonios de quienes pelearon contra los norteamericanos y aquéllos que fueron testigos presenciales. Inicia el libro con una lista de los hombres y mujeres que murieron en el puerto en ese año. Su estilo es ameno y sencillo y deja entrever el apoyo de la autora a la tierra natal.

COLMEX Mentz, Brigida Von, Verena Radkau, Beatriz 325.43 Scharrer y Guillermo Turner, Los pioneros del im0972 perialismo alemán en México, México, Centro de P662 Investigaciones y Estudios Superiores de Antropo522 p. logía Social, Ediciones de la Casa Chata, 1982,

Este trabajo intenta contribuir al conocimiento de la sociedad mexicana del siglo XIX analizando uno de los grupos que la conformaron, el de los alemanes. Se plantean cuestiones que tienden a contestar preguntas sobre su origen, actividades, procesó de adaptación, vinculaciones politicas y efectos sobre lo que se califica como sociedad receptora. Dentro del análisis social, político y económico que se realiza, el puerto de Veracruz y la forma en que los inmigrantes alemanes se asimilaron a la sociedad regional ocupan un lugar relevante. El uso de documentación primaria y los numerosos cuadros sobre establecimientos, industrias y compañias manejadas a través del capital alemán facilita también la identificación de intereses vinculados a la economia veracruzana.

SHCP

9(726.1)

$\mathrm{M}$

Merino, Antonio, La conspiración veracruzana de 1812. Pról. de Leonardo Pasquel, México, Editorial Citlaltépetl, 1960, 82 p. (Colección Suma Veracruzana, Serie Historiografía.)

BCUVX

972.61

Reproducción de un manuscrito del siglo XIX M562c que no se limita a relatar acontecimientos del periodo insurgente, sino que comprende sucesos de 1837. Antonio Merino, en un intento por explicar su remoción del resguardo de la Aduana Marítima de Veracruz, dirige una carta a sus hijos en la que describe su actuación durante la guerra de independencia y las que él llama injusticias dé los gobiernos federales de 1837 y 1842 . El texto resulta de interés por las opiniones que se vierten en él, reflejo de una época.

BCUV(PR)X Naredo, José Ma., Estudio geográfico, histórico y 8035-36 $14792-93$ estadistico del cantón de la ciudad de Orizaba, Orizaba, Imprenta del Hospicio, 1898, 2 vols.

Estudio monográfico cuyo valor radica en el hecho de que el autor fue testigo de muchos de los hechos que relata. 
De origen orizabeño, Naredo pretende no sốlo conservar el pasado histórico de su ciudad natal, sino dar a conocer información sobre el cantón que facilite su conocimiento por medio de material geografico y estadístico. Una de las pocas obras que permiten adentrarse en la región orizabeña del siglo XIX.

INAH Padúa, Cándido Donato, Movimiento revolucionaBNA rio, 1906 en Veracruz, relación cronológica de las F330 actividades del P.L.M. en los ex-cantones de AcaP3 yucan, Minatitlán, San Andrés Tuxtla y centro del pais, Tlalpan, s.e., 1941, 196 p.

BCUV(PR)X La finalidad del autor es referir los aconteci23358 mientos con la mayor objetividad posible y dedicar el productō de su venta a la compra de una imprenta que le permita publicar un periódico revolucionario. Su contenido está basado en documentación poco conocida que relata la sublevación de 1906 en el sur de Veracruz y en Tabasco, destacando la participación de algunos revolucionarios, sus fracasos y sus intrigas. Incluye una especie de biografia de Hilario Salas, el pacto de unión fimado en Catemaco en 1908, cartas de los principales dirigentes y testimonios de la injerencia de Santana Rodriguez en las filas del Partido Liberal.

BMRX Pardo, Emilio, El ferrocarril de Veracruz, México, 4078 Impresores de F. Díaz de León y Santiago White, $1868,16 \mathrm{p}$.

Texto que reproduce la polémica surgida entre Emilio Pardo y Manuel Payno en la que el primero acusa al segundo de haber apoyado la construcción del ferrocarril a Veracruz durante la intervención francesa. Los alegatos de uno y otro ponen de manifiesto los intereses involucrados en esta empresa y las diversas concepciones que se tenian sobre la misma.

ENV(JM)X Pasquel, Leonardo, Ignacio de la Llave, México, 972

$\mathrm{P}$ Editorial Citlaltépetl, 1981, p. 164.

De las más amplias biografias de este liberal veracruzano, oriundo de Orizaba. El autor menciona haber consultado el archivo personal de de la Llave además de hemerografía y bibliografía secundaria, de manera que, aun cuando el tono de la obra no es crítico, proporciona en cambio suficiente información que, aunada a documentación municipal o notarial, permite reconstruir las actividades del personaje al mismo tiempo que se explica el contexto local.

BCUVX Pasquel, Leonardo, El conflicto obrero de Rio c/a Blanco en 1907, México, Ed. Citlaltépetl, 1976, 104 p. (Colec. Suma Veracruzana. Serie HistorioSHUVX $\mathrm{c} / \mathrm{a}$ grafia.)

Estudio centrado en los sucesos de Rio Blanco en 1907. Entre los temas que trata podemos señalar los siguientes: la industria textil orizabeña (Cocolapan), antecedentes laborales, el liberalismo veracruzano y el socialismo, como factores del movimiento obrero; la rivalidad Dehesa-Limantour, desconocido proyecto de legislación laboral; huelga y paro, decla- 
ración de principios del gran círculo de obreros, liberales de Río Blanco, el arbitraje presidencial, la represión militar, escarmiento y consecuencias.

Según se puede apreciar, el número de temas es elevado, pero están manejados o estudiados en forma resumida. Se incluyen fotografias, abundante bibliografia y hemerografia. No tiene introducción.

INAH

REF

F1371

P38

Pasquel, Leonardo, Gobernadores del Estado de Veracruz, 1821-1982, México, Ed. Citlaltépetl, 1982,450 p. (Colec. Suma Veracruzana. Serie Gobernadores del Estado.)

El estado de Veracruz ha tenido 110 gobernadores, la mayoría de ellos provisionales e interinos. En el libro aparecen ordenados cronológicamente de acuerdo a la fechas en que fueron gobernadores, empezando con Pedro Telmo de Landero en 1812 hasta 1982 con Agustín Acosta Lagunes. Como este estudio trata las biografias de personalidades, en ellas se encuentra información sobre su participación política, militar y económica en la época en que les tocó vivir.

COLMEX Pasquel, Leonardo, La generación liberal veracru080

S9551

p2 zana, México, Ed. Citlaltépetl, 1972, 366 p. (Colec. Suma Veracruzana. Serie Biografías.)

Obra que contiene casi 60 biografias de liberales veracruzanos y aunque carece de bibliografía, la IIHUVX verdad es que constituye la única forma de conoc/a cer los antecedentes familiares, la formación, actividades, intereses y ambiciones de un grupo politico que fue determinante para la consolidación política del estado de Veracruz. Quizás parte de su información deba ser tomada con alguna reserva, pero, en términos generales, resulta una obra de consulta básica para el análisis de la economía o de la política locales.

BCACX Pasquel, Leonardo, La rebelión agraria de Acayuc/a can en 1906, México, Ed. Citlaltépetl, 1976, 62 p. (Colec. Suma Veracruzana. Serie Historiografía.)

El autor nos da un panorama general sobre la rebelión agraria de Acayucan en 1906. Para ello analiza como antecedente la situación geográfica de Acayucan remontándose a la llegada de Cortés, para después centrarse en los años de 1900 en adelante.

El libro está estructurado de la siguiente manera: la región de Acayucan y los clubes liberales de la comarca; dos inversiones del suegro del dictador de Acayucan; Hilario C. Salas; el ataque de Acayucan; mi participación revolucionaria por Enrique Novoa; mi cautiverio en San Juan de Ulúa; apéndice por Miguel Alemán. Abundante bibliografía, índice. No hay introducción.

INAH

LBS

F1391

V4

P38
Pasquel, Leonardo, La revolución en el Estado de Veracruz, México, Talleres Gráficos de la Nación, 1971, 2 vols.

Un estudio preliminar inicia el texto en el cual el autor justifica su obra y plantea sus concepcio- 
nes acerca de la revolución en el país y en Veracruz. El primer tomo comprende desde los movimientos precursores del levantamiento armado de 1910 hasta 1911. El segundo parte de las renuncias de Diaz, en el gobierno federal, y Dehesa, én la administración estatal, para pasar a ocuparse del régimen maderista y llegar al constitucionalismo. La bibliografia es abundante así como la hemerografía utilizada, fuentes que no son accesibles para el público.

FHUVX Pasquel, Leonardo, La invasión de Veracruz en c/a 1914, México, Ed. Citlaltépetl, 1976, 136 p. (Colec. Suma Veracruzana. Serie Historiografía.)

El libro está estructurado en 4 partes; la primera trata de los antecedentes, es decir, la politica entre los Estados Unidos y México siendo presidentes Porfirio Diaz y Taft respectivamente, hasta la época de Woodrow Wilson. La segunda parte se refiere a la invasión, la tercera corresponde a la ocupación y la cuarta a la desocupación, en donde se destaca la participación del general Cándido Aguilar, gobernador y comandante militar del estado.

Contiene fotografías de los campamentos y defensores veracruzanos. Abundante bibliografía y hemerografía sobre la invasión dé 1914. No tiene introducción.

BCACX Pasquel, Leonardo, Manuel Gutiérrez Zamora, c/a México, Editorial Citlaltépetl, 1977, 120 p. (Colec. Suma Veracruzana. Serie Gobernantes del Estado SHUVX de Veracruz.)

c/a Estudio biográfico apoyado en hemerografía y bibliografia secundaria que, al igual que otros de este autor, intenta recrear el ambiente en el que se desenvolvió Gutiérrez Zamora y seguir el hilo conductor de su carrera política y de sus intereses económicos estrechamente vinculados al comercio del puerto de Veracruz. La obra, que comprende el periodo que va de 1813 a 1861 , facilita información que es de gran utilidad para la comprensión de la sociedad local.

\section{BJDCX Pasquel, Leonardo, Manuel y José Azueta-padre e c/a hijo-héroes de la gesta de 1914. México, Editorial \\ Citlaltépetl, 1967, 218 p. (Colec. Suma Veracru-} zana. Serie Biografías.)

En este libro se publican juntas dos biografias, la del padre y del hijo, porque ambos fueron marinos en la etapa de la ocupación del puerto de Veracruz por las fuerzas norteamericanas en 1914, y ambos combatieron a los invasores. El padre de uno y abuelo del otro. Manuel F. Azueta, también combatió a otros invasores, los franceses, entre 1862 y 1867 . De manera que el autor considera más que justificado su esfuerzo por reconstruir dos vidas a través de las cuales se profundiza en un acontecimiento histórico determinado.

BJDCX Pasquel, Leonardo, Xalapeños distinguidos, Méxic/a co, Ed. Citlaltépetl, 1975, 692 p. (Colec. Suma Veracruzana. Serie Biografías.)

Se trata de un diccionario biográfico. Surgió como un compro- 
miso que el autor se impuso para estudiar a su tierra natal a través de diversos aspectos y difundirlos entre las nuevas generaciones.

El libro es importante porque dentro de las biografias de los personajes estudiados se encuentran datos históricos, económicos o políticos que en algún momento pueden enriquecer un nuevo tema de investigación.

$\mathrm{El}$ índice consiste en una lista de los hombres biografiados. Tiene introducción.

BCUVX Payno, Manuel, Memoria sobre la revolución de c/a diciembre de 1857 y enero de 1858, México, Imprenta de I. Cumplido, 1860, $137 \mathrm{p}$.

Con lenguaje claro y conciso Payno brinda un relato de los acontecimiento que motivaron el golpe de estado de Tacubaya en diciembre de 1857. Su exposición pretende ser una "narración verdadera" de los hechos en los que tomó parte activamente, justificando tanto su posición como la del resto de los involucrados entre los que sobresale Ignacio Comonfort. La obra resulta de gran interés para la historia veracruzana porque señala la injerencia que tuvo el gobierno de Veracruz en el cambio político y las circunstancias que rodearon su despronunciamiento y posterior definición poṛ la causa constitucionalista.

IIHUVX Payno, Manuel, Un viaje a Veracruz en el invierno c/a de 1843, Pról. de Esther Hernández Palacios, Puebla, Talleres Gráficos de Premiá, 1984, 131 p. (Universidad Veracruzana. Colección Rescate, núm. 1.)

Payno, novelista clásico de la literatura mexicana del siglo XIX, demostró su calidad de observador de costumbres y aspectos de la vida de provincia en las crónicas que a manera de cartas dirigió a su amigo Fidel, seudónimo de Guillermo Prieto, y que fueron publicadas en 1844 con el título de esta obra. En ellas el autor relata un viaje lleno de vicisitudes y hace agudas observaciones sobre los integrantes, usos y costumbres de la sociedad veracruzana de esa época. Bello documento para reconstruir el pasado regional, acompañado en esta reedición de dos crónicas más: La Cascada de la Orduña y Cacería de venados en Orizaba.

BCUVX Pérez, Abel R., Teodoro A. Dehesa, gobernante vec/a racruzano, México, Impreso en los Talleres Stylo, $1950,85 \mathrm{p}$.

Breve esbozo biográfico apoyado en información facilitada al autor por un hijo del gobernante, Raúl Dehesa. Se presenta un panorama de su actuación política resaltando los acontecimientos de 1907 y el inicio de la Revolución mexicana.

BMRX Pérez de León, José, Historia gráfica de la invac/a sión americana, Veracruz, 1914, Xalapa, s.p.i.

El objetivo del autor es reseñar la oposición presentada por un grupo de cadetes de la Escuela Naval, a las fuerzas norteamericanas que ocupaban el puerto. Es una historia gráfica que reproduce a los personajes principales de ambos bandos, tanto políticos como militares; los combates que se dieron en diferentes posiciones y un croquis de Veracruz en 1914. 
INAH

LBS

F1391

$\mathrm{J} 2$

P6 .

BCUVX

917.261

P891m

Poyet, C. F., Monografia de Xalapa, 1863, Pról. de Leonardo Pasquel, México, Ed. Citlaltépetl, 1962, 40 p. (Colec. Suma Veracruzana. Serie Viajeros.)

El autor de estas memorias era un médico militar francés que acompañaba al ejército enviado a México en 1861 por Napoleón. Desde 1862, fecha en que el doctor Poyet llegó a Xalapa; se arraigó en esa capital veracruzana.

Poyet hace una descripción del paisaje, enfermedades y costumbres de los habitantes de esa ciudad. Según Leonardo Pasquel, la monografía nos permite conocer a Xalapa tal como se encontraba hace cien años, conservando su fisonomía típica y tradicional. También tiene información sobre la economia regional, el modo tranquilo de la población, la relevancia de su cultura y la belleza de sus mujeres.

La obra fue escrita en francés, y en la capital apareció por primera vez en el periódico "La sociedad", incluida en fracciones los dias del 22 al 27 de junio de 1864.

BCUVX Prieto, Guillermo, Una excursión a Jalapä en $\mathrm{c} / \mathrm{a}$ 1875, Pról. de Leonardo Pasquel, México, Editorial Citlaltépetl, 1968, 360 p.

FHUVX c/a

Esta obra se publicó por partes en la Revista Universal, de 1875 a 1876 . Pasquel la rescató del olvido localizándola en la Hemeroteca Nacional, la reeditó y le agregó algunas notas explicativas en relación con los personajes mencionados por Prieto. El escrito consiste en las cartas que el autor remitió al Nigromante desde Xalapa, mientras efectuaba una excursión en dicha población. El estilo es muy ameno y las descripciones locales de mucha utilidad. Prieto recrea el ambiente de toda una época y nos deja además una serie de observaciones' sobre economia, industria, agricultura, educación, recursos naturales y sociedad.

ENV(JM)X Ramírez Lavoignet, David, La independencia en 972

'R Misantla, Jalapa-Enríquez, s.e., 1967, 186 p.

La publicación de la presente obra se debe a que el 23 de marzo de 1967 se celebró el sesquicentenario de la heróica defensa del pueblo de Misantla y de su total aniquilamiento. Se celebra como el glorioso esfuerzo de un pueblo que se siente libre y que agotó todas sus energías ante la fuerza del -enemigo hasta morir... pues a la postre ganó la batalla al consumarse la independencia nacional en 1821 .

Los testimonios que aqui se presentan sobre la independencia en Misantla, constituyen un ensayo histórico que no pretende ser obrá integral, ni materia sometida a prudente crítica; son retazos de noticias, convertidas en curiosa investigación sin mayor interés que el de desentrañar los contenidos de la historia veracruzana. Dice el autor que la mayor parte de las fuentes son virreinales, pues las contemporáneas no se han encontrado, o fueron quemadas.

Como capítulo medular tenemos: Primeras inquietudes para la independencia (p. 69 a 180). Tiene introducción, notas, indice y bibliografia primaria y secundaria. 
BNAL

923.272

RAMI.c.

SHUVX

c/a

Ramirez Lavoignet, David, Los constituyentes federales veracruzanos, 1917, Jalapa-Enriquez, Gobierno del Estado Libre y Soberano de Veracruz, 1979,320 p.

Proporciona las biografías de los veracruzanos presentes en el congreso constituyente de 1917, que habían sido seleccionados de los 19 distritos que tenía entonces el estado y que de alguna forma habían participado en la Revolución mexicana para derrocar a Porfirio Díaz.

Aunque el título sólo menciona el año de 1917, en cada uno de los biografiados se encuentra información sobre su actuación revolucionaria entre 1900 y 1907.

Cuenta la obra con prólogo, introducción e índice, y está dividida de acuerdo con una lista de los biografiados, Cándido Aguilar. Silvestre Aguilar, Heriberto Jara, entre otros. Al final de cada biografia se encuentra la bibliografía que consiste en fuentes bibliográficas secundarias y hemerografía.

BJDCX Ramírez Lavoignet, David, Misantla, Pról. de Leo972 nardo Pasquel, México, Ed. Citlaltépetl, 1959, 268

R

A-7441

$\mathrm{CPX}$

972

R p. (Colec. Suma Veracruzana. Serie Historiografía), 2a. ed.

Reedición. El propósito del autor ha sido responder aquí a una serie de preguntas que comúnmente suelen hacerse los habitantes de todos los. pueblos: ¿Cuándo se fundó el pueblo?, ¿quienes lo fundaron? ¿de dónde vinieron los pobladores? ¿quienes le pusieron este nombre? etc. Fuera de ello, el autor espera que tenga alguna utilidad para complementar tratados diversos. El trabajo está dirigido a los habitantes y originarios del municipio de Misantla, al honorable ayuntamiento constitucional, a los familiares del autor, a sus amigos, y al licenciado Leonardo Pasquel, que se propuso editarlo.

Según Pasquel, resulta ser la obra más amplia, penetrante y mejor informada sobre el lugar. Los capítulos medulares para el siglo XIX son: la Independencia, la Invasión norteamericana, el Imperio y la República, zafarrancho de castas. Es narrativa, de carácter oficial. haciéndose raras referencias a otros pormenores. Tiene una presentación preliminar del autor, abundante bibliografía primaria y secundaria.

ENV(JM)X

972

R

BCUVX

c/a
Ramírez Lavoignet, David, Tantoyuca, notas históricas arregladas por David Ramírez Lavoignet, Jalapa-Enriquez, Universidad Veracruzana-Seminario de Historia, 1971, 82 p.

Esta tesis fue realizada por el maestro David Ramirez Lavoignet, con la finalidad de que sirviera de base a las actividades de la pasantía o servicio social, contribuyendo en buena manera a proporcionar información para las personas que anhelan datos históricos, y que no se pueden atender por la falta de una biblioteca de ese tipo en el Seminario de Historia. Dice que la historia debe ser una investigación exhaustiva y crítica, considera que su trabajo no cumple 
con esa finalidad realmente, mucho menos cuando se abstiene de manejar documentos de primera mano, al formular una monografia desde su escritorio. Para ello -dice- "Hace falta entrevistar a maestros, vecinos, ancianos que pudieran recordar los acontecimientos realizados en una generación, así también consultar archivos, hemerotecas y bibliotecas". Su intención es sólo que despierte la curiosidad y provoque inquietud de investigación. Dirigida al pueblo de Tantoyuca, hace un estudio completo sobre el lugar, destacando todos los aspectos; analiza el problema agrario, las rebeliones agrarias, la propiedad territorial a finales del siglo xIX y principios del XX. También habla de la independencia, vida independiente, revolución social y dotación ejidal; Toponimias nahuas, toponimias huastecas. Tiene bibliografía primaria y secundaria.

ENV(JM)X Ramírez Lavoignet, David, Tecolutla, monografia 972

R histórica, Jalapa-Enríque, Universidad Veracruzana-Seminario de Historia, 1981, 142 p.

Esta investigación se realizó como parte de un proyecto del Seminario para hacer monografias de poblaciones y municipios del estado de Veracruz. En ella colaboró el H. Ayuntamiento de Tecolutla en la persona del Lic. Sergio Hernández Méndez, quien proporcionó datos y fotografias.

La preocupación en la presente investigación fue la tenencia de la tierra y las actividades religiosas. Tecolutla inició una nueva ruta histórica en 1921 , fecha en que se solicitan tierras para dotación ejidal, se desarrolla el turismo, etcétera.

Capítulos sobre el siglo XIX: independencia y época independiente, invasión, colonización, porfiriato y revolución. Abundante bibliografia primaria y secundaria.

BCUVX Ramírez Lavoignet, David, Tlapacoyan, Jalapa, 972.61 Universidad Veracruzana, 1965, 214 p. (CuaderT626r nos de la Facultad de Filosofia, Letras y Ciencias, 32.)

Libro dirigido a la heroica ciudad de Tlapacoyan; su publicación fue tributo de reconocimiento y gratitud por haber sido teatro de memorable batalla el 22 de noviembre de 1865 .

Ramirez hace una historia completa de la ciudad, tomando en cuenta desde el medio físico, la época prehispánica hasta que se le da el nombre de ciudad (antes era municipio), sin dejar de tocar temas importantes como el movimiento independiente, la colonización francesa, intervención francesa, época independiente (1831-1881) y el periodo revolucionario.

Tiene datos sobre población de 1893 a 1930 , toponimias del municipio y hombres inolvidables; abundante bibliografía primaria y secundaria.

ENV(JM)X Ramírez Lavoignet, David, Soteapan, luchas agra-

972

R

BCUVX

$\mathrm{c} / \mathrm{a}$ rias, Jalapa-Enríquez, Universidad Veracruzana, Seminario de Historia, 1971, 67 p.

Este es un trabajo mimeografiado. Se da un panorama general de la Historia de Soteapan desde sus primeros pobladores, hasta 1964. Como capítulos medulares se pueden señalar las leyes sobre 
división de comunidades indígenas; los terrenos baldios; división de comunidades en el cantón; la división de comunidades en Soteapan; las tierras del Lic. Manuel Romero Rubio; reflexiones (sobre la tenencia de la tierra en Soteapan); la rebelión indigena y él Partido Liberal Mexicano.

Según se puede apreciar, casi toda la información que ofrece èl maestro Ramírez Lavoignet corresponde a la historia de Soteapan en la segunda mitad del siglo XIX y primeras décadas del XX.

En lugar de introducción habla de la población actual. Tiene indice y amplia bibliografia secundaria.

BNAL

972.61

RIV.h

BCUV(PR)X $\mathrm{c} / \mathrm{a}$

Rivera Cambas, Manuel, Historia antigua y moderna de Jalapa y de las revoluciones del Estado de Veracruz, México, Imprenta de Ignacio Cumplido, $1869-1871,5$ vols.

Obra considerada como una de las dos historias generales clásicas con que cuenta la historiografia veracruzana. Dice el autor que consultó una gran variedad de archivos locales, algunos archivos particulares como el de Antonio Ma. de Rivera y el de Alonso Güido y Güido, y numerosos manuscritos de la época sin mayor información. Su contenido va de las culturas prehispánicas al imperio de Maximiliano. Su estilo es cronológico y a veces detallista. En la actualidad hay investigadores que ponen en duda la veracidad de algunos de los datos que proporciona, pero su valor no desmerece por ello puesto que reseña la época que vivió.

IIHUVX Roa Barcena, José Ma., Noche al Raso, Pról. de c/a Jorge Ruffinelli, Puebla, Talleres Gráficos de Premiá, 1984, 252 p. (Universidad Veracruzana. Colección Rescate, núm. 2.)

Escrita por uno de los escritores más leídos y gustados del siglo $\mathrm{XIX}$, que destacó por su prosa bien cuidada, tersa y castiza, ofreció bellas estampas costumbristas. Jalapeño de filiación conservadora, considerado como el iniciador del cuento moderno, produjo una serie de relatos que constituyen clásicos de la narrativa breve, y se reúnen bajo este título. Con frecuencia utilizó la literatura como arma política en favor de los intereses de la reacción esforzándose por demostrar la "locura" de efectuar cambios radicales y destacar la razonable alternativa de conservar el orden establecido. Su lectura es obligatoria para conocer la concepción de una época y de una región.

BNAL

REV

972.09:86 RODR.d.

Rodriguez, Alberto A., Don Pascual, o la invasión de Veracruz por los americanos en 1914. Novela histórica mexicana formada con la compilación metódica, comentada y concordada de documentos oficiales $y$ particulares $y$ de las informaciones de la prensa de Veracruz, México y otras ciudades, París-México, Librería de la Vda. de Ch. Bouret, 1920, 392 p.

La novela está dedicada a la heroica ciudad de Veracruz. El autor fue testigo presencial de la invasión de los americanos al primer puerto de la República; escribe esta obra porque no quiso dejar en el olvido ni el menor de los detalles de este ataque a 
México; además, su intención no era desvirtuar la verdad histórica.

El estilo que adóptó para su narración ha tenido dos objetivos: primero, que sea una válvula de escape a la aridez de la historia; segundo, presentar a la opinión pública este suceso por medio de personajes ficticios.

BCUVX Sánchez Durán, Aurelio, "Veracruz: división terric/a torial federalista, 1824-1832", La Palabra y el Hombre, Xalapa, Revista de la Universidad Veracruzana, núm. 52, octubre-diciembre 1984 , p. 95-102.

La validez de este artículo radica en el hecho de reproducir parte de la estadística del Veracruz de 1831, una fuente regional poco accesible. Su objetivo primordial fue poner de relieve la división territorial federalista de la entidad, cómo fue aceptada y cuáles fueron las consecuencias de su aplicación. El resumen de población y un mapa territorial que proporciona son de gran ayuda en el contexto regional.

SHUVX .Sánchez Durán, Aurelio, "Reseña sobre las guerric/a llas insurgentes de Puente Nacional", Revista de Investigaciones Históricas, Xalapa, Seminario de Historia, núm. 1, 1979, p. 95-121.

Crónica de los sucesos que durante la guerra de independencia tuvieron lugar en torno de Puente Nacional, la importancia de la posición y las acciones militares desarrolladas ahí. Apoyada en fuentes secundarias, la bibliografia se incluye en el texto que no tiene ningún tipo de divisiones y que concluye con unas reflexiones finales.

IIHUVX Sánchez Gómez, Rosa Catalina, El Encero: histoc/a ria de una hacienda jalapeña (Tesis de Lic. en Historia), Xalapa, Universidad Veracruzana, ,Facultad de Historia, $1970,84 \mathrm{p}$.

Este trabajo tuvo como finalidad estudiar la evolución de la tenencia de la tierra, tomando como punto central las haciendas que se localizaron en la región de Xalapa. Para ello se escogió la hacienda El Encero situada al sur de Xalapa. La falta del archivo particular de esta propiedad hizo que el trabajo quedara circunscrito a la elaboración de los cambios que experimentaron sus terrenos desde el siglo XVI, cuando empezó a consolidarse la gran propiedad, hasta el siglo $\mathrm{XX}$, durante el cual culminó el proceso de desintegración de la hacienda iniciado en el último tercio del siglo pasado.

De acuerdo con la información obtenida en los archivos generales se pudo comprobar que El Encero fue una empresa agroindustrial, cuyas actividades comprendian la explotación pecuaria, las industrias de la alfarería y de hilados y tejidos de algodón y el cultivo y procesamiento de la caña de azúcar y del henequén.

Como capitulos medulares podemos señalar los traspasos y arrendamientos de la hacienda (1724-1882); la compañia agrícola y manufacturera "El Encero" (1900-1952); la afectación agraria y la población beneficiada. Bibliografía y hemerografia primaria y secundaria. 
BCUVX

$\mathrm{c} / \mathrm{a}$

Santiago Cruz, Francisco, San Juan de Ulúa; biografia de un presidio, México, Ed. Jus, 1966, 142

p. (Colec. México Heroico núm. 61.)

El autor de este libro hace una descripción de lo que fue el Castillo de San Juan de Ulúa, desde la llegada de los españoles hasta el siglo XIX.

Entre los temas que trata se encuentran: la guerra de los pasteles, la guerra de 1847, Miramón en Veracruz, la Triple Alianza, alimentación y reglamento de los presos en San Juan de Ulúa; fiebre amarilla, invasión de 1914. Sólo tiene índice y dos páginas de bibliografía secundaria.

BCUV(PR)X Segura, Vicente, Apuntes para la estadistica del c/a Departamento de Orizaba, formada por su Jefe ciudadano Vicente Segura, y dedicados al excelentisimo señor gobernador del Estado Libre de Veracruz, ciudadano Miguel Barragán, en el año de 1826, Jalapa, Oficina del Gobierno por Aburto y Blanco, 1831.

Este libro se publicó después de transcurrido un quinquenio de haber sido escrito. El autor realizó una síntesis histórica nutrida de acontecimientos y observaciones importantes sobre las jurisdicciones políticas de Zongolica, Córdova, Huatusco y Cosamaloapan que integraban ese departamento de acuerdo con la primera constitución veracruzana del 3 de junio de 1825 .

No existía entonces otro trabajo de estadística completo para el primer lustro de nuestra vida independiente. Abarca muchos aspectos.

COLMEX
O80
S955s
BJDCX
972
S
A-7452

COLMEX
Sehara, Ismael, Huatusco, breves apuntes para la historia de esta ciudad y su jurisdicción. Estudio preliminar de Leonardo Pasquel, México, Ed. Citlaltépetl, 1965, 192 p. (Colec. Suma Veracruzana. Serie Historiografia.)

Publicada por partes en periódicos locales, la primera edición completa apareció en 1922,debido a que se iba a celebrar el primer centenario de la definitiva emancipación política del país. El gobernador Adalberto Tejeda quiso hacer justicia al autor de esta obra, ya que sus virtudes han permanecido dormidas e ignoradas en el anonimato. En 1965 Pasquel lo reimprimió aumentándole diversos grabados para su mejor ilustración.

La obra está divida en cinco épocas y comprende desde los tiempos primitivos hasta la restauración de la República y los tiempos más recientes (1876). Más adelante habla de apuntes históricos acerca de la guardia nacional en el cantón de Huatusco de 1855 a 1876, los sucesos de Jamapa en 1859 redactados en forma de novela y menciona a la gente de Huatusco. Para terminar habla de las mejoras que se hicieron en Huatusco a finales del siglo XIX.

El autor dedica su obra a su hija Enriqueta, para que a través de la lectura ame, respete y bendiga la tierra en que nació. Ella a su vez, la dedica a sus paisanos en 1921.

No tiene bibliografía y la introducción de Pasquel se refiere al autor. 
INAH

FOL

F1371

s728e

Southworth, John R., El Estado de VeracruzLlave; su historia, agricultura, comercio $e$ industria, en inglès y español, México, publicado bajo la dirección y autorización del gobierno del estado, $1900,159 \mathrm{p}$.

BMRX Esta publicación ha sido precedida por Sonora 5811 Ilustrado, Sinaloa Ilustrado y Baja California Ilustrado, del mismo autor.

La publicación de El Estado de Veracruz estuvo apoyada por el gobernador Teodoro A. Dehesa. Dice el autor que no hay en el continente norteamericano un país tan rico y productivo como el estado de Veracruz, abundante en recursos naturales, rico en bosques, tabaço, café, vainilla, caña de azúcar y arroz; solamente faltaba la mano de obra moderna.

Soutworth hace una descripción histórica de Veracruz desde la conquista española hasta la intervención francesa. Después hace un estudio breve de los diferentes temas, entre ellos industria del azúcar, café, principales haciendas de caña, ganado, etcétera.

Tiene estadísticas e ilustraciones. No tiene bibliografía.

BCUVX Staples, Anne, "Esfuerzos y fracasos: la educación c/a en Veracruz, 1824-1867", La Palabra y el Hombre, Xalapa, Revista de la Universidad Veracruzana, núm. 52, octubre-diciembre 1984, p. 35-54.

Artículo bien estructurado, con un amplio uso de fuentes documentales, que proporciona una visión global del desarrollo educativo en Veracruz, en especial en la región central de la entidad en donde se ubican las cuatro poblaciones de mayor importancia: Xalapa, Veracruz, Córdoba y Orizaba. Se describen las disposiciones estatales y se vinculan esfuerzos y resultados con los acontecimientos nacionales y regionales.

COLMEX

972.61

T794h

BCUVX

c/a
Trens, Manuel B., Historia de Veracruz, Xalapa, Talleres Gráficos del Gobierno del Estado; 1947-1950, 8 vols.

La segunda de las obras consideradas clásicas en la historia de Veracruz, que explica con amplitud y profundidad los acontecimientos históricos locales que van de 1519 a 1910. La obra tiene una buena estructura y aparato crítico y refleja las opiniones del autor. Quizás la parte que se refiere al porfiriato y al inicio de la Revolución resulte un poco superficial. Sin embargo, en conjunto, está considerada como de consulta obligada. Proporciona una amplia bibliografía aunque ya no es posible localizar muchas de las fuentes indicadas.

SHUVX Urias Hermosillo, Margarita, "Manuel Escandón: c/a de las diligencias al ferrocarril. 1833-1862", en Formación y Desarrollo de la Burguesia en México, Siglo XIX, México, Editorial Siglo XXI, 1978, 286 p.

La primera de una serie de investigaciones que constituyen un gran esfuerzo precursor del desarrollo de la historia social y económica del siglo xIX y que, en este caso particular, proporciona una serie de datos que permiten cuestionar algunos aspectos de la composición social veracruzana. La autora sitúa el comporta- 
miento y la práctica social de un hombre de empresa, Manuel Escandón, de origen veracruzano, en una sociedad preindustrial que tendía a reorganizarse de acuerdo con los intereses político-económicos aparecidos en la etapa final del periodo colonial. Profundiza en la conformación de grupos sociales nuevos y establece vinculaciones entre diferentes facciones e intereses que pretenden explicar, en cierta forma, los procesos históricos del México independiente.

ENV(JM)X Veracruz. Gobierno del Estado, Acayucan y Rio c/a Blanco, gestas precursoras de la Revolución, Jalapa, Gobierno del estado de Veracruz-Dir. Gral. de Educación, 1964, 76 p. (Biblioteca del Maestro Veracruzano, 7.)

Este libro fue publicado por la Dirección General de Educación con la finalidad de divulgar los movimientos de Soteapan y Acayucan en 1906, y Río Blanco en 1907. Está dedicado al pueblo que se enfrentó al déspota en tales acontecimientos. Se basa en dos entrevistas realizadas a don Hilario Gutiérrez, persona destacada durante el movimiento de 1906, y a don Melitón T. Martínez y doña Lucrecia Ortíz, partícipes de los hechos de Río Blanco. La primera entrevista se hizo en 1950 al celebrarse el 40 aniversario de la Revolución mexicana; apareció en "La Opinión" de Minatitlán, Ver. y posteriormente en "El Popular" de México, D. F. La segunda se efectuó en 1957 con motivo del cincuentenario de los acontecimientos obreros, y vio la luz en el diario "La Opinión". El entrevistador fue el profesor Angel J. Hermida.

Independientemente del aspecto histórico e informativo, se trata de un homenaje a quienes cayeron en aras de un México democrático cuando la dictadura se sentía aún poderosa. Interesante, sobre todo porque es trabajo a base de entrevistas.

COLMEX Ward, Henry George, México en 1827. Selección, $972.051 \quad$ México, SEP/FCE, 1985, $203 \mathrm{p}$.

W256m El autor, encargado de negocios británicos en

México, siguiendo la costumbre implantada por las grandes potencias de enviar gente ilustrada a informar sobre paises enemigos o colonias en perspectiva, exploró la nación cuando apenas habia alcanzado su independencia. Pese al enfoque oficial de sus observaciones, su libro puede servir a la historia regional y aun resulta una lectura agradable pues examina un país y una sociedad en formación en un periodo calificado como de "mal gobierno". Para el caso de Veracruz resultan de gran interés los capítulos III, IV y $\mathrm{V}$ en los cuales el autor relata su llegada a la población porteña, su estancia en ella y su ascenso al Altiplano.

COLMEX

92

S2311y

Yáñez, Agustín, Santa Anna, espectro de una sociedad, México, Ediciones Océano, 1982, 264 p.

Publicado después de la muerte del autor, es un intento de presentar las posibilidades que existen para analizar la polémica personalidad de Antonio López de Santa Anna desde perspectivas novedosas, al margen de las concepciones tradicionales. Dado que el caudillo veracruzano fue figura central del panorama veracruzano del siglo XIX, la lectura de la obra 
de Yáñez es de gran ayuda para comprender las causas y consecuencias de su influencia y carisma a partir del concepto del hombre "providencial" producto del romanticismo de la época. Se maneja con habilidad la tesis del caudillo como espejo que refracta los elementos diferenciados de la sociedad del periodo independiente.

SHCP
$9(726.1)$
$Z$
ENV(JM)X
972
$Z$

Zilli, Juan, Historia sucinta del Estado de Veracruz, Jalapa-Enriquez, s.e., 1943, 159 p.

Esta historia de Veracruz, más que libro de texto, son apuntes para que los alumnos y maestros los consulten y a la vez conozcan los hechos más notables de la tierra veracruzana. Está escrita en forma sencilla y ordenada cronológicamente. Presenta hechos militares, politicos y culturales y comprende desde los primeros pobladores hasta 1942 . Tiene apéndice de gobernadores de 1824 a 1950 , veracruzanos distinguidos, hombres ilustres originarios de otros lugares del país y del extranjero. No tiene bibliografía. Se publicó una segunda edición en la Editorial Citláltepetl en 1962.

BCUV(PR)X Zilli Bernardi, Juan, Reseña histórica de la educaC/a- ción pública en el Estado de Veracruz, Xalapa, Gobierno del Estado de Veracruz, 1966, 2 t.

IIHUVX El propósito del autor fue salvar del olvido los c/a afanosos empeños que para mejorar la educación se hicieron en el estado y ofrecerlos a las generaciones de hoy y de mañana, con sus triunfos y sus fracasos. Sin embargo, dice el autor "ésta mi obra, no intenta mayores méritos, pues se reduce a simple traslación y compaginación de datos, documentos, noticias, informes, referencias, diseminados por aquí y por allì". Pero a pesar de todo no está exenta de valor; otros con más herramientas ahondarán en el estudio y sacarán a relucir nuevos tesoros.

La historia abarca desde el periodo prehispánico hasta el gobierno de Fernando López Arias para el tomo I. El tomo Il está constituido por apéndices. Tiene bibliografía y hemerografía secundaria.

BCUVX $\mathrm{C} / \mathrm{a}$

Zilli Mánica, Benigno, "Franceses e italianos en México", La Palabra y el Hombre, Xalapa, Revista de la Universidad Veracruzana, núm. 49, enero-marzo 1984, p. 21-51.

Reproducción de los relatos de dos excolonos del siglo XIX. El primero describe uno más de los intentos de colonización francesa que se efectuaron en la región del Coatzacoalcos entre 1830 y 1831. La expedición es descrita por Mathieu de Fossey, un empresario particular que con sus obreros y su capital quiere fundar un establecimiento. El segundo constituye una especie de entrevista hecha a un colono italiano anónimo encuadrado en la organización oficial llevada a cabo por el gobierno mexicano en tiempos del presidente Manuel Gónzalez.

Ambos relatos tienen una estructura semejante en la que interviene una gran variedad de actores, de circunstancias y matices que, como señala el autor, constituyen el "recuento del embrujo 
ejercido por el lejano país que se imagina lleno de vitalidad desde una Europa anquilosada y rigida, el viaje que sólo en sí es ya una aventura, la colonia y el desengaño posterior con el abandono de los propósitos que habían determinado la venida a estas tierras.

BCIVX Zilli Mánica, José Benigno, Italianos en México, c/a Xalapa, Ediciones San José, 1981, 515 p.

Obra que reproduce una serie de documentos para SHUVX la historia de los colonos italianos en México, una c/a . gran parte de los cuales se asentaron en suelo veracruzano asimilándose a los procesos históricos regionales en medio de contradicciones y crisis. El autor pretende que se vea con mayor "simpatía y comprensión" a través de nuevas perspectivas, a hombres de siglos remotos que abandonaron un contexto conocido para seguir "quimeras americanas" formando parte del proceso colonizador nacional. Logra realizar el "dossier de sus papeles" para presentar la descripción de su internación y establecimiento en el país.

BCUVX Zilli Mánica, José B., "Proyectos liberales de coloc/a nización en el siglo XIx", La Palabra y el Hombre, Xalapa, Revista de la Universidad Veracruzana, núm. 52, octubre-diciembre 1984 , p. 129-142.

Descripción de las circunstancias en que intentó ponerse en marcha un proyecto de colonización para establecer en el camino Xalapa-Veracruz cuatro colonias: El Chico, Rinconada, Paso de Ovejas y Tejería. El autor, especialista en el tema; describe la forma en que dicho proyecto fue auspiciado por el gobierno liberal de 1856 y tratado de poner en práctica por las autoridades veracruzanas sin gran éxito. En ese entonces la política de colonización parecia sostener una especie de "receta mágica": la libertad y la colonización indiscutiblemente traerian el progreso y la modernidad anhelada.

Bibliotecas consultadas

BCACX: Biblioteca Pública Carlos A. Carrillo. Xalapa

BCUVX: Biblioteca Central de la Universidad Veracruzana.

Xalapa

BCUV(PR)X: Biblioteca Central de la Universidad Veracruzana,

Colección Pedro Rendón. Xalapa

BMRX: $\quad$ Biblioteca Matias Romero del Inmecafé. Xalapa

BNAL: Biblioteca Nacional

BJDCX: Biblioteca Pública Juan Diaz Covarrubias. Xalapa

COLMEX: Biblioteca de El Colegio de México

CPX: Biblioteca del Colegio Preparatorio. Xalapa

ENV(JM)X: Biblioteca José Mancisidor de la Escuela Normal

Veracruzana. Xalapa

FHUVX: $\quad$ Biblioteca de la Facultad de Humanidades de la Universidad Veracruzana. Xalapa

IIHUVX: Biblioteca del Instituto de Investigaciones

INAH: Humanisticas de la Universidad Veracruzana. Xalapa

INAH: Biblioteca del Instituto Nacional de Antropología e Historia

SHCP: . Biblioteca de la Secretaria de Hacienda y Crédito

SHUVX: $\quad$ Búblico $\quad$ Biblioteca del Seminario de Historia de la Universidad Veracruzana. Xalapa

c/a:clasificación por autores 